\title{
Heat Transfer Tests of Ribbed Surfaces for Gas-Cooled Reactors
}

\author{
O. H. Klepper
}

\section{OAK RIDGE NATIONAL LABORATORY}




\section{DISCLAIMER}

This report was prepared as an account of work sponsored by an agency of the United States Government. Neither the United States Government nor any agency Thereof, nor any of their employees, makes any warranty, express or implied, or assumes any legal liability or responsibility for the accuracy, completeness, or usefulness of any information, apparatus, product, or process disclosed, or represents that its use would not infringe privately owned rights. Reference herein to any specific commercial product, process, or service by trade name, trademark, manufacturer, or otherwise does not necessarily constitute or imply its endorsement, recommendation, or favoring by the United States Government or any agency thereof. The views and opinions of authors expressed herein do not necessarily state or reflect those of the United States Government or any agency thereof. 


\section{DISCLAIMER}

Portions of this document may be illegible in electronic image products. Images are produced from the best available original document. 
Printed in the United States of America. Available from National Technical Information Service

U.S. Department of Commerce

5285 Port Royal Road, Springfield, Virginia 22161

Price: Printed Copy $\$ 5.45$; Microfiche $\$ 2.25$

This report was prepared as an account of work sponsored by the United States Government. Neither the United States nor the Energy Research and Development Administration, nor any of their employees, nor any of their contractors, subcontractors, or their employees, makes any warranty, express or implied, or assumes any legal liability or responsibility for the accuracy, completeness or usefulness of any information, apparatus, product or process disclosed, or represents that its use would not infringe privately owned rights. 
ORNL-TM-4108

UC-77 - Gas Cooled

Reactor Technology

Contract No. W-7405-eng-26

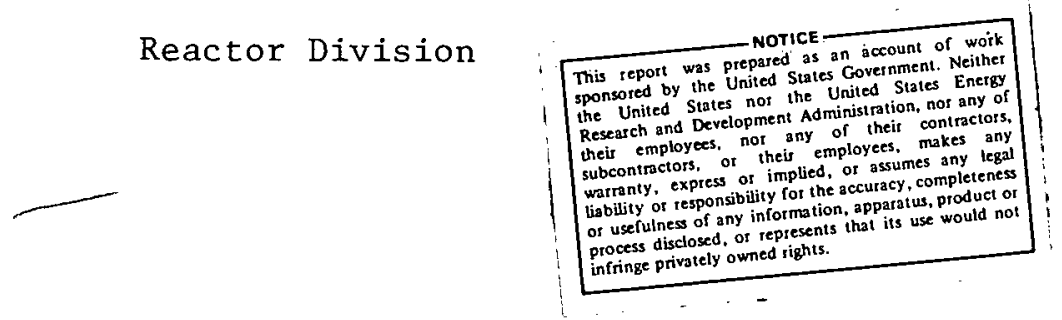

HEAT TRANSFER TESTS OF RIBBED SURFACES

FOR GAS-COOLED REACTORS

O. H. Klepper

JULY 1975

OAK RIDGE NATIONAL LABORATORY

Oak Ridge, Tennessee 37830

Operated by

UNION CARBIDE CORPORATION

for the

U.S. ENERGY RESEARCH AND DEVELOPMENT ADMINISTRATION 
THIS PAGE

\section{WAS INTENTIONALLY LEFT BLANK}


CONTENTS

$\underline{\text { Page }}$

Acknowledgement $\ldots \ldots \ldots \ldots \ldots \ldots \ldots \ldots \ldots \ldots \ldots \ldots \ldots \ldots \ldots \ldots$

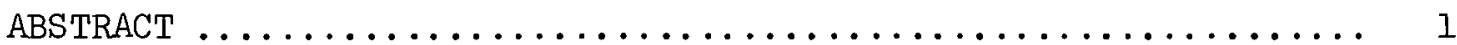

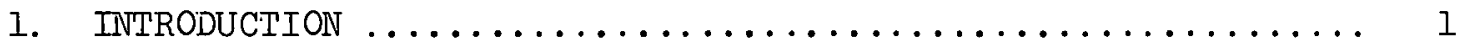

2. EXPERIMENTAL EQUIPMENT AND PROCEDURES $\ldots \ldots \ldots \ldots \ldots \ldots \ldots \ldots \ldots$

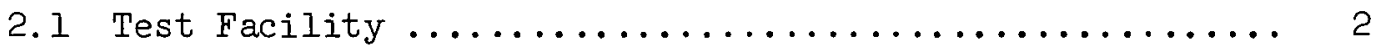

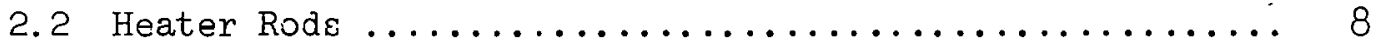

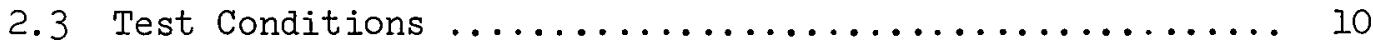

3. D.ATA REDUCTION AND TRANSFORMATIONS $\ldots \ldots \ldots \ldots \ldots \ldots \ldots \ldots \ldots \ldots$

3.1 Heat Transfer Calculations ................... 14

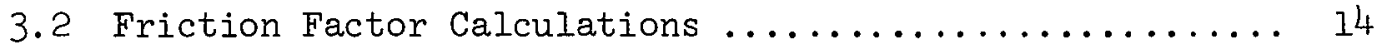

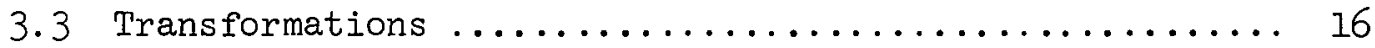

3.3.1 Friction Factor Transformation ............ 18

3.3.2 Stanton Modulus Transformation ............ 21

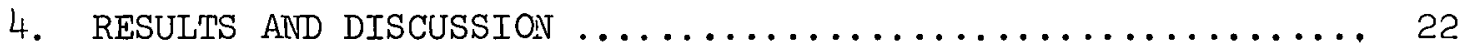

4.1 Pressure Drop Results ..................... 22

4.2 Heat Transfer Results ..................... 26

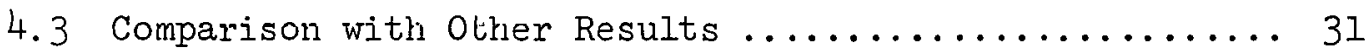

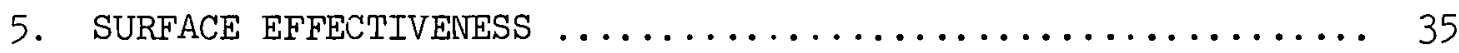

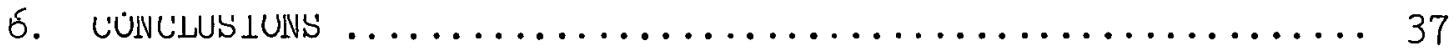

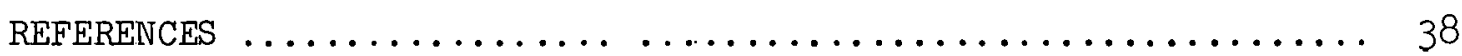

LIST OF SYMBOLS ........................... 4

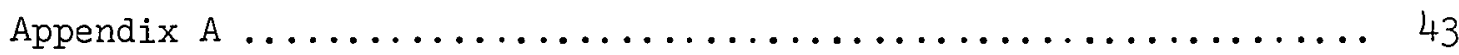


THIS PAGE

\section{WAS INTENTIONALLY \\ LEFT BLANK}


This research, performed at the Oak Ridge National Laboratory, was sponsored by the U. S. Atomic Energy Commission under contract with Union Carbide Corporation.

The author is grateful for the assistance given by $R$. H. Jones in the design of the test section and for that by J. W. Krewson in the development of the test loop and the associated instrumentation. D. L. Clark's help in the design and procurement of the heater rods, as well as General Atomics Company's cooperation in the preparation of the test surfaces, is gratefully acknowledged. G. Markóczy was most helpful by providing comparative test results obtained at the Eidg. Institut für Reaktorforschung in Würenlinge, Switzerland, and by suggesting some useful methods for data analysis.

For the preparation of the report I thank Margie Adair and Viola Erickson. 


\section{HEAT TRANSFER TESTS OF RIBBED SURFACES \\ FOR GAS-COOLED REACTORS}

O. H. Klepper

ABSTRACT

The performance of gas-cooled reactors is often limited by the heat transfer in the reactor core. The present studies have investigated means for modifying core heat transfer surfaces to improve their performance. Experiments were conducted to evaluate several rod surfaces roughened by GA for ORNL. The 0.3-in. -OD stainless steel clad heater rods were photoetched to produce external ribs $0.006 \mathrm{in.} \mathrm{high} \mathrm{and} 0.12$ in. wide with a pitch of 0.072 in. Helical ribs with a helix angle of $37 \mathrm{deg}$ (to promote interchannel flow mixing in a multirod array) were provided on one surface. For comparison purposes, a transversely ribbed surface and a smooth rod were also studied. The test surfaces were 49 in. long with a 24-in. heated region, concentrically arranged inside a smooth $0.602-i n$. -ID stainless steel tube. Nitrogen gas at pressures up to $400 \mathrm{psig}$ was used as the coolant; the linear heat rating ranged to $6.8 \mathrm{~kW} / \mathrm{ft}$ at surface temperatures up to $1400^{\circ} \mathrm{F} ; \mathrm{T}_{\mathrm{W}} / \mathrm{T}_{\mathrm{b}}$ varied from 1.2 to 2.4 at $R e$ values up to 450,000 . Annulus results were recalculated for rod geometry using two different transformations. Good agreement was observed with applicable literature values.

The effectiveness of the surfaces was assessed as the ratio $E$ of the heat transfer coefficients of the roughened rods to that, of a smooth red at the $\varepsilon$ ame pumping power. The effectiveness of the spiral ribs ranged from 1.3 to 1.4 , and from 1.2 to 1.4 for the transverse ribs, spanning Re values from 60,000 to 400,000. These data include variations introduced by alternate transformation methods that were used to make annulus test results applicable to rod geometry.

The surfaces investigated in these tests were considered for fast gas-cooled reactors; however, the range of parameters studied also applies to heat transfer from ribbed rod-type fuel elements in thermal gas-cooled reactors.

\section{INI'RÖLUC'I'LONN}

The performance of gas-cooled reactors is often limited by the heat transfer in the reactor core. One direct method for increasing the heat transfer rates is to raise the flow velocity; however, any gain is quickly 
lost to the more rapid rise in pumping power. Hence, a more profitable approach lies in the search for ways to modify the fllow and/or the surface in order to enhance the heat transfer without an excessive increase in the pressure drop. Studies in these directions ${ }^{1,2}$ have been underway at the Oak Ridge National Laboratory for several years, and a test facility has been developed capable of investigating the heat transfer behavior of a variety of tube and rod surfaces in gaseous flow at pressures up to $1000 \mathrm{psig}$ and temperatures up to about $1200^{\circ} \mathrm{F}$.

The objective of the present test was to study the heat transfer and pressure drop characteristics of specif'ic enhanced heat transter surt'aces considered by General Atomics ${ }^{3}$ for potential use in advanced f'ast gas-cooled reactors. Cylindrical rod surtaces, photoetched by GGA to produce external ribs, were to be tested in annular geometry using nitrogen gas at pressures up to $400 \mathrm{psig}$ as coolant, with surface temperatures to reach up to $1400^{\circ} \mathrm{F}$ at linear heat ratings up to three $\mathrm{kW} / \mathrm{ft}$. Under these conditions the nitrogen tests (expressed in terms of a nondimensional relationship of the Nusselt modulus as a function of the Reynolds and Prandtl moduli), would simulate thermally and dynamically the heat transfer and flow for high performance helium-cooled reactors that might operate in the pressure range from 1000 to 1200 psig with linear heat ratings up to $14 \mathrm{~kW} / \mathrm{ft}^{\circ}$ and wall temperatures reaching $1400^{\circ} \mathrm{F}$.

\section{EXPERIMENTAL EQUIPMENT AND PROCEDURFS}

\subsection{Test Facility}

A schematic arrangement of the test equipment fur unce-Liruugl operation with either helium or nitrogen gas at up to L'CU psIg piressure is shown in Fi.g. 2.1. For clarity not all thermocouples are plctured. In the present series of tests, the coolant was nitrogen gas supplied from a trailer truck that contained up to $2400 \mathrm{lb}$ at 1600 psig.

The gas pressure in the flow channel was controlled by a pressure regulator located upstream of the gas preheater. Most of the runs were conducted at about 200 psig; a number of runs, primarily those at higher flow rates, were run at 400 psig. The gas flow rates were measured using 


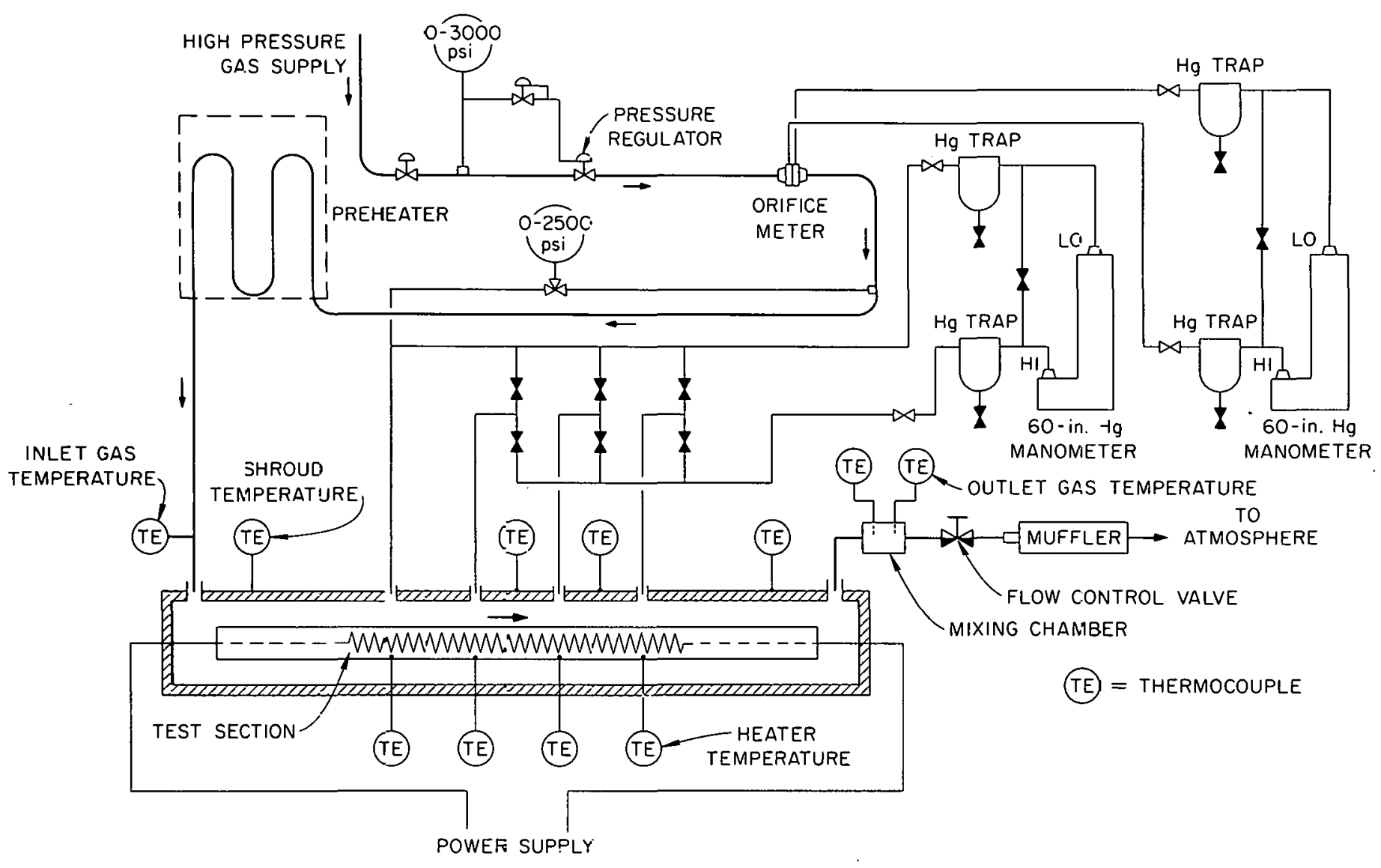

Fig. 2.1. Test facility schematic diagram. 
an ASME type orifice meter that had been calibrated over the range 0.01 to $0.13 \mathrm{lb}_{\mathrm{m}} / \mathrm{sec}$ at $200 \mathrm{psig}$ nitrogen gas pressure using three FisherPorter rotameters. The rotameters in turn had been calibrated with a positive displacement meter that showed them to be accurate and precise to within $\pm 1 \%$. The orifice meter pressure and the test channel pressure were obtained with a 0 to 2500 psig Heise gage. The pressure drop across the 0.437-in. ID sharp-edged orifice of the flowmeter and between the pressure taps along the heated length of the flow channel.was obtained with a Series 500 Exactel Servomanometer designed to measure pressure drops of up to $60 \mathrm{in}$. to within $\pm 0.004 \mathrm{in}$. over the full range of system pressure.

Downstream of the orifice meter the gas entered an ohmically heated preheater ( $150 \mathrm{~kW}$ capacity) connected to two saturable reactors in parallel, which supplied an alternating current at up to $30 \mathrm{~V}$. The preheater exit temperature, which ranged from ambient up to $760^{\circ} \mathrm{F}$, was measured by two chromel-alumel thermocouples. inserted into the gas stream. From the preheater, the gas flowed into the pressure shell that housed the test section. As shown in Fig. 2.2, each heater rod was located inside a flow shroud in concentric annular flow geometry. Streamlined centering spacers were brazed to ach heater rod at 120-deg azimuthal intervals at the axial positions shown in Fig. 2.2. The test section was set vertically in order to minimize deflection of the heaters, Examination of the heating surfaces after completion of the tests gave no indication of misalignment. The shroud, depicted in Fig. 2.3, consisted of a 304 SS tube, 0.600-in.-ID and 0.065-in.-wall thickness. Gas pressure drop measurements in the heated region were obtained from 0.030-in. -ID holes provided in the shroud wall at 90-deg azimuthal intervals at each of four axial positions abreast of the heater rod thermocouples (see Fig. 2.2). The pressure shell, depicted in Fig. 2.4, was designed to accommodate shrouds containing rod clusters with up to seven heaters. The void space between the flow shroud and the pressure shell and also the exterior surface of the pressure shell were insulated thermally with Kaowool. The coolant gas entered the pressure shell at four circumferential points $90 \mathrm{deg}$ apart in order to promote azimuthal flow symmetry. The flow was dispersed further by a perforated baffle through which the gas passed before it entered the 
ORNL - DWG $73-3764$

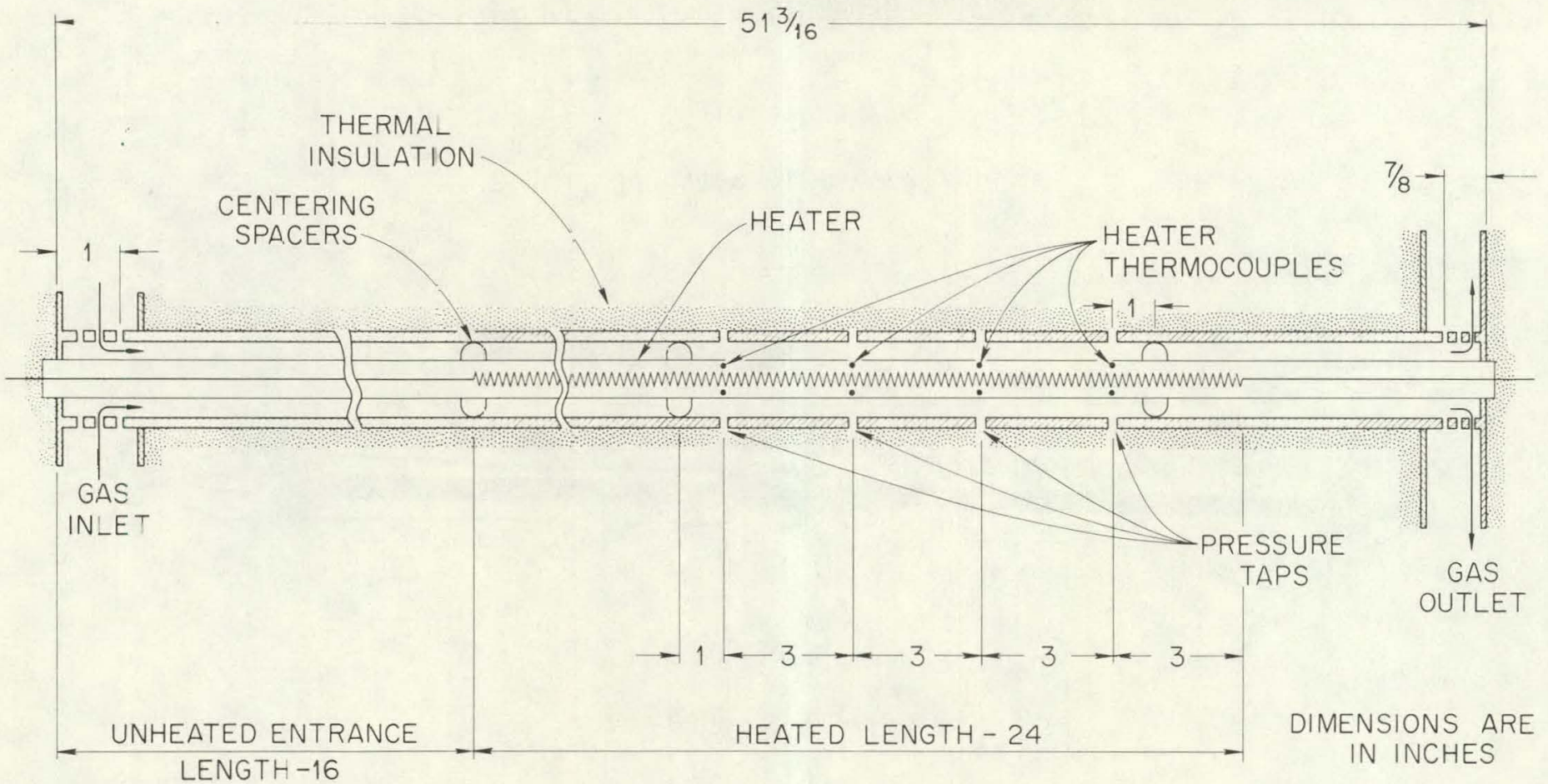

Fig. 2.2. Test channel arrangement. 


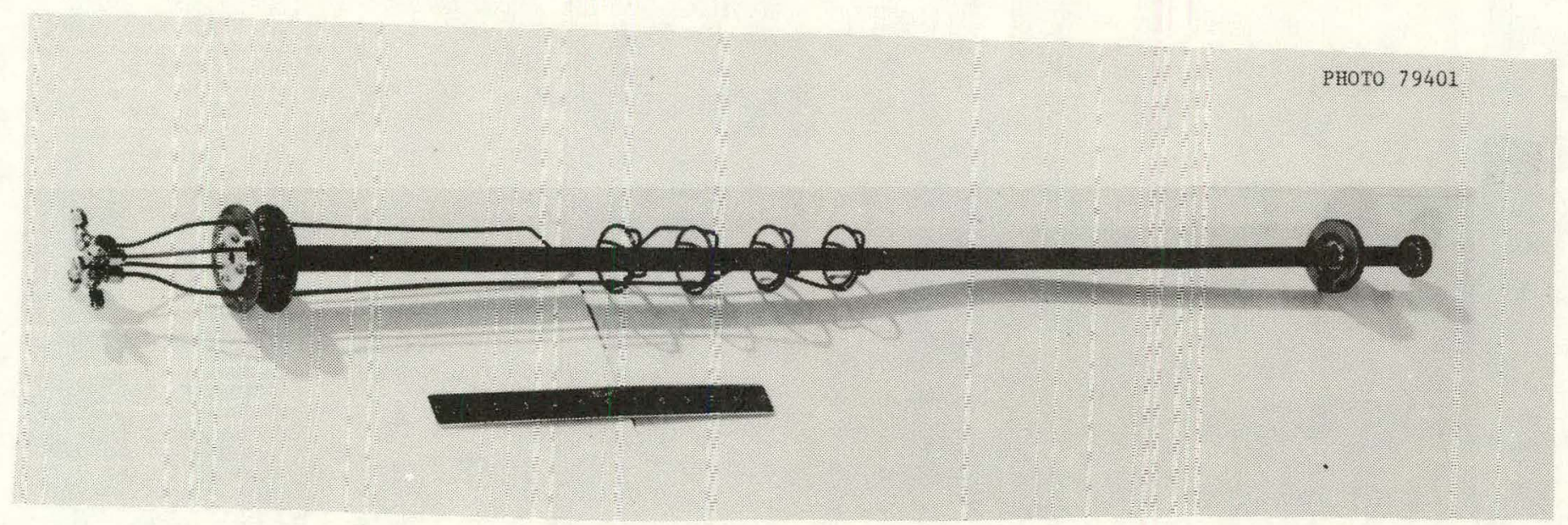

Fig. 2.3. Vies of flow shroud. 


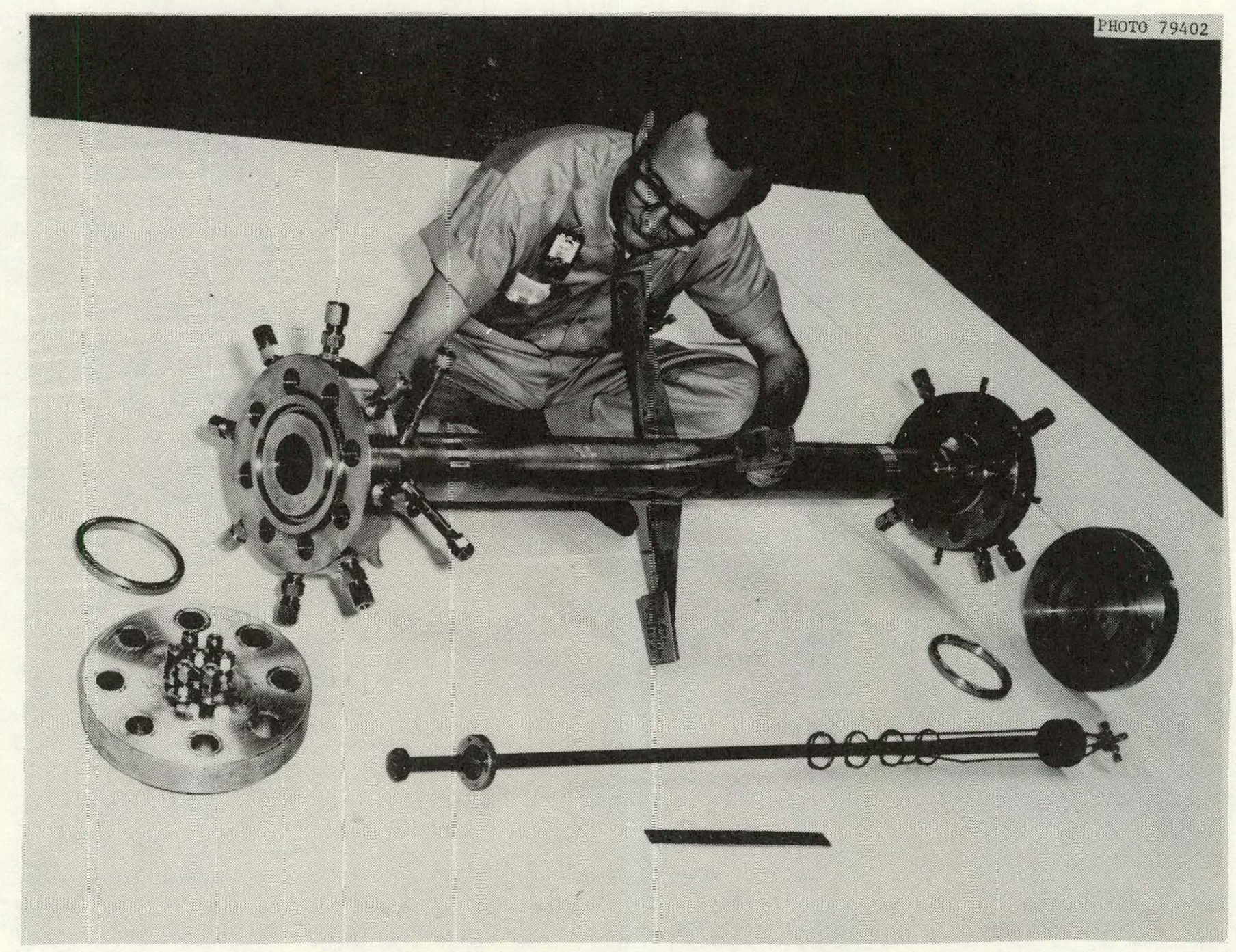

Fig. 2.4. View of pressure she11 and flow shroud. 
annulus. The flow arrangement at the exit to the annulus was similar. The exit region of the test assembly before the application of insulation is depicted in Fig. 2.5. Chromel-alumel thermocouples spotwelded to the exterior of the flow shroud and the pressure shell were used to obtain the temperatures needed to determine the heat loss to the environment. The gas exit temperature was measured with a sheathed chromelalumel thermocouple inserted into the flow downstream of a mixing section to assure a good mixed mean temperature.

Signals from the thermocouples employed in the test were displayed on four multipoint Brown recorders and on two two-point line recorders. Electrical power for the heater rod was supplied from four stacked variacs with a capacity of $24 \mathrm{~kW}$ al 200 volts ac. The voltage across the test section was measured with a Fluke digital voltmeter accurate to within $+0.05 \%$. The current was read from a precision Weston ammeter accurate to within $\pm 0.75 \%$ that was fed by a $20: 1$ current transformer.

\subsection{Heater Rods}

The heater rods manufactured ${ }^{4}$ by the Watlow Electric Manufacturing Company of St. Louis, Missouri, were dimensionally protutyple of nuclear fuel rods considered for use in advanced gas-cooled fast breeder reactors. The 2-ft-long heated section consisted of a closely wound helical coil of Nichrome-V wire located concentrically wilhin lle 304 SS heater sheaths and separated from them by compacted boron nitride. Each end of the heating coil was connected to a 0.125-in.-OD copper lead-in conductor. Eight sheathed and grounded type $\mathrm{K}$ chromel-alumel thermocouples of 0.020 in. OD were located in four 0.020-in. by 0.020-in. axial grooves machined 90 deg apart on the outer periphery of the 0.037-in.-thick inner sheath. The thermocouples were held in place by a 0.012-in. -thick outer sheath swaged onto the inner sheath. The thermocouples were arranged to provide two diametrically opposite measuring points at each of the four axial locations shown in Fig. 2.2. Each pair of thermocouples was oriented 90 deg apart azimuthally t'rom the adjacent pair. The sheath thermocouples were located well within the heated length so that temperature measurements would be unaffected by end losses. Examination of heater radiographs revealed that the heater coil eccentricity did not exceed 0.015 in. and the variation in the number of coils per inch was generally 


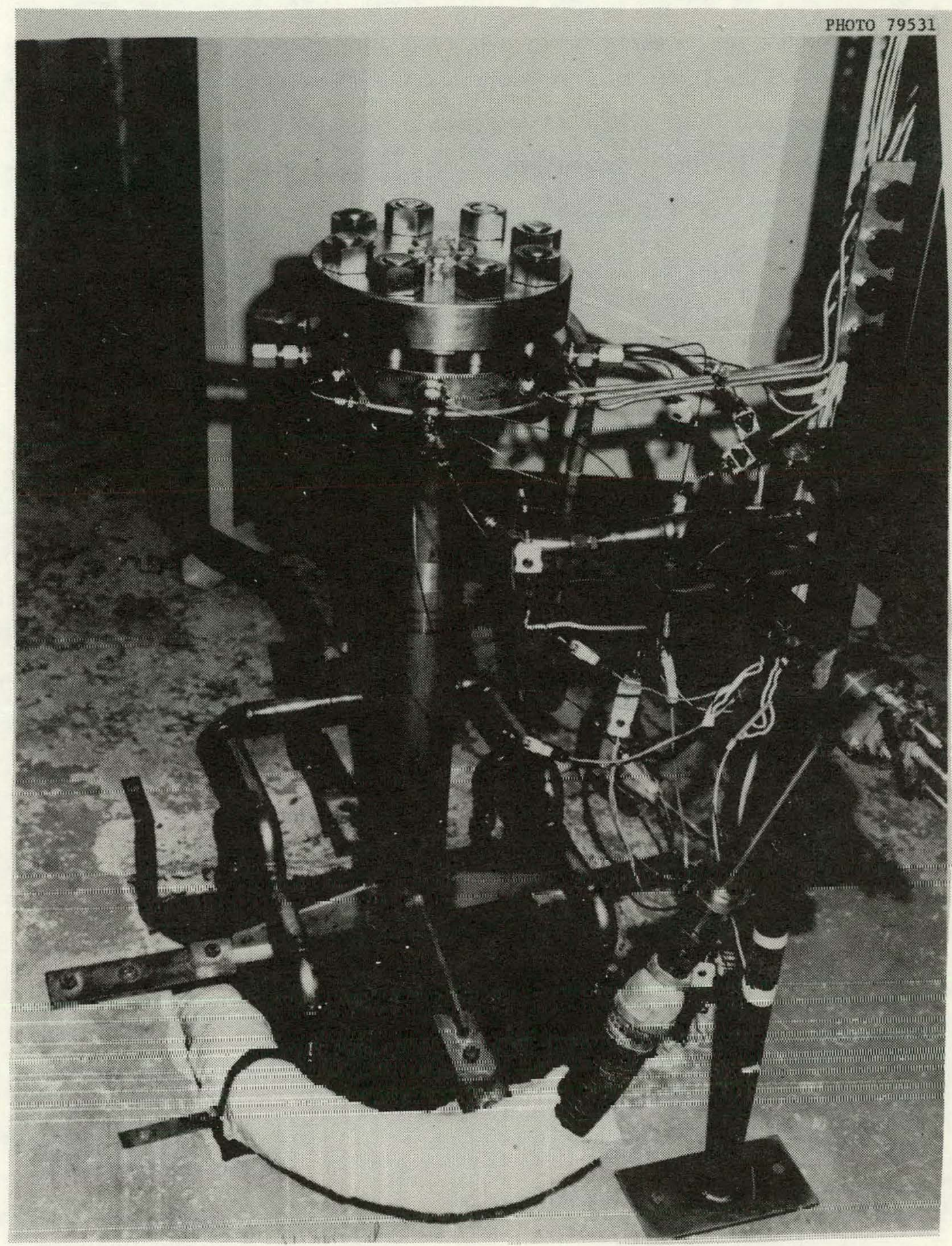

Fig. 2.5. View of test assembly in place. 
less than $\pm 1 \%$; it was estimated lhat these discrepancies would not perturb the uniformity of the heat flux significantly. The heat flux distribution of the heaters was also checked ${ }^{5}$ using a high-speed scanning infrared camera. In those tests an electric current was passed through the heating coil under steady-state and transient conditions while the heater surface temperatures were scanned for nonuniformity. A heating current was also applied to the heater sheath during a transient test to determine local temperature peaks resulting from poor contact between the sheath and the boron nitride insulation. The results of the scanning tests suggested that the heat flux distribution of the heater rods would be satisfactory.

Three heaters with different surfaces were tested. Hcater rod A had a smooth exterior surface of 0.302 in. OD. The surface of heater $B$ depicted in Fig. 2.6 was photoetched to within about 2 in. of each cnd to produce helical fins $0.006 \mathrm{in}$. high and $0.012 \mathrm{in}$. wide with a pitch of $0.072 \mathrm{in.}$ and a helix angle of $37 \mathrm{deg}$. The fin dimensions were fairly uniform although the fillet radius at the fin base varied somewhat from place to place. The etched surfaces did not appear as smooth as the original rod surface. This was confirmed with surtace roughness measurements performed with a profilometer, which showed a roughness of 40 to $65 \mu \mathrm{rms}$ for the etched surfaces vs 15 to $20 \mu \mathrm{rms}$ for the original surface. 'I'he outside didmeler of the lieatcr wad $0.289 \mathrm{in}$. excluning the height of the fins. Heater $\mathrm{C}$ was roughened by the same technique to produce fins of approximately the same height, width, and spacing, but in ring geometry Instead of a helical configuration. As dopicted in Fig. ?.7, the degree of fin shape uniformity and surface roughness appears similar to those observed for heater B. The outside diametcr was 0.288 in.

\subsection{Test Conditions}

The testing program was designed to measure the heat transfer and pressure drop characteristics of the vurious surfaces undcr steady-state conditions. Test conditions were considered sufficiently stable if system temperatures and flow rates did not change more than about $1 \%$ while 

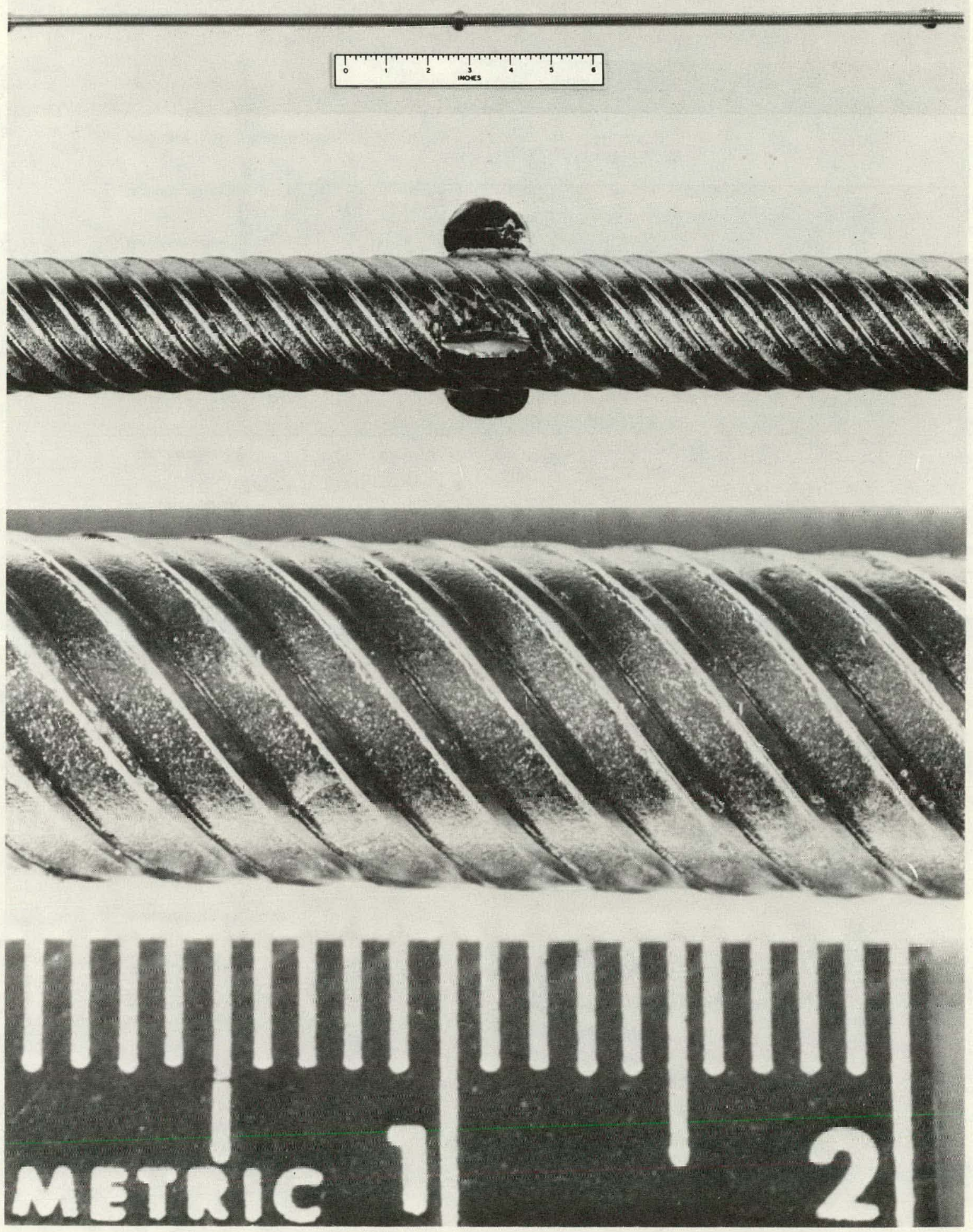

Fig. 2.6. View of helically ribbed surface, heater B. 

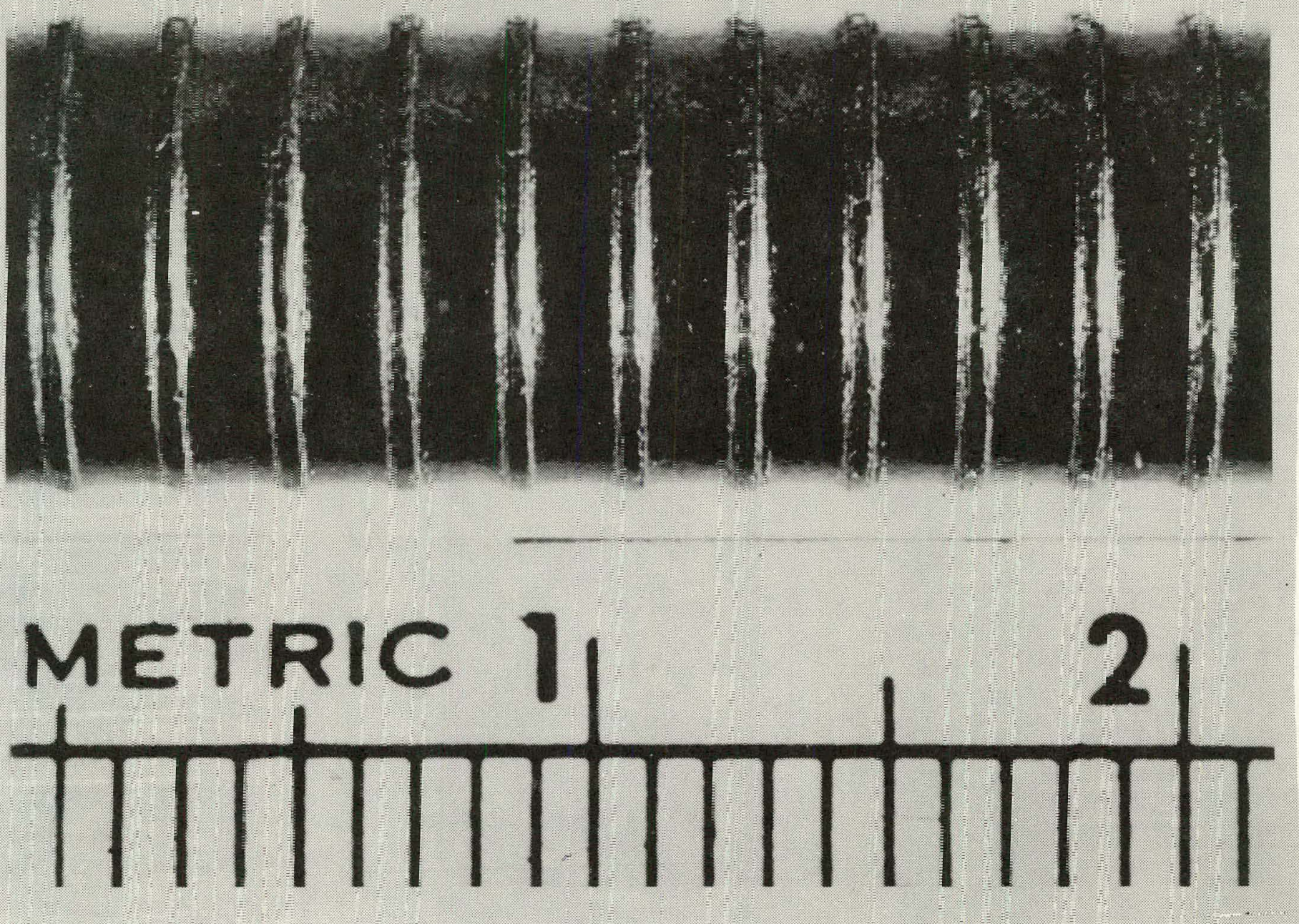

Fig. 2.7. View of transversely ribbec surface, heate= C. 
the data were being recorded, involving a time period of five to ten minutes duration. Because of its mass and associated thermal inertia, the gas preheater required a two to three hour warmup period before stable operation could be achieved. The test sequence was planned to minimize the variation of gas inlet, gas outlet, and peak heater surface temperatures between successive runs in order to reduce the time required to approach steady state.

About 170 test runs were completed including 38 tests to determine heat losses and adiabatic pressure drops. The linear heat rates reached were $4.4,6.7$, and $6.8 \mathrm{~kW} / \mathrm{ft}$, respectively, for heaters A, B, and C. This was well below the peak design capability of $12 \mathrm{~kW} / \mathrm{ft}$ available for tests possibly using helium gas as a coolant. The peak power delivered by the preheater was $21.1 \mathrm{~kW}$; gas flow rates ranged from 0.01 to $0.21 \mathrm{~b} / \mathrm{sec}$. The Reynolds moduli reached up to 450,000 and heat fluxes reached values in excess of $300,000 \mathrm{Btu} / \mathrm{hr} \cdot \mathrm{ft}^{2}$ at surface temperatures up to $1400^{\circ} \mathrm{F}$. The test section gas exit temperature reached $1100^{\circ} \mathrm{F}$ and $\mathrm{T}_{\mathrm{W}} / \mathrm{T}_{\mathrm{b}}$ ranged from 1.2 to 2.4 .

\section{DATA REDUCTION AND TRANSFORMATIONS}

\subsection{Heat Transfer Calculations}

A computer program written in FORTRAN IV and listed in Appendix A was used to analyze the heat transfer and pressure drop measurements obtained during the tests. For purposes of calculation, the test length was divided into seven axial segments. Three of these segments were located in the instrumented region of the heater rod with their boundaries coinciding with the heater thermocouple locations (see Fig. 2.2).

The heat transfer computation was begun by performing a heat balance over the test section. The energy gained by the gas (as inferred from the gas flow and the gas temperature rise) and the heat lost through the insulation was summed and compared with the electrical energy supplied to the experiment. Runs with a discrepancy greater than 5\% were discarded. The electrical conductivity of the Nichrome heating coil, and consequently its heat generation rate, was assumed uniform along the heated length, 
introducing a potential error of less than $0.7 \%$ in the value of the heat flux. The rate of gas energy gain in each segment was calculated from:

$$
Q_{g}=Q_{e}-Q_{l}
$$

where $Q_{e}$ is the rate of electrical heat generation and $Q_{l}$ is the loss through the insulation. The gas enthalpy rise was calculated from:

$$
\Delta H=Q_{g} / W
$$

where $W$ is the mass t'Low rāte. 'l'he lôcāl gas enthulples were delermLued by adding the enthalpy rise in each segment. The local gas pressure was calculated from measurements in the flow channel assuming linear pressure variation, thus determining the gas state in each segment. The properties of nitrogen gas were computed from two computer subprograms, TABHP and TABTP taken from Ref. 6.

The heater sheath temperatures were measured by thermocouples located in the inner sheath. The outer surface temperatures were then determined by calculating the radial temperature gradient assuming a uniform heat flux. The thermal conductivity of the sheath material was based on the local temperature.

Having determined the local gas and surface temperatures as well as the local gas energy gain, the calculation of heat transfer coefficients and various nondimensional groupings was straightforward.

\subsection{Friction Factor Calculations}

For analyzing the pressure drop measurements, each test section was analytically divided into three segments with boundaries defined by the location of the pressure taps as shown in F'ig. '2.2.

The computer calculations of the experimental friction factors and associated parameters used gas properties obtained in the heat transfer analysis. The observed pressure drops were corrected to remove contributions from changes in axial flow velocity. Accelerations were due to changes in gas density and in channel flow area; thus: 


$$
\Delta P_{\text {friction }}=\Delta P_{\text {measured }}-\Delta P_{\text {density }}-\Delta P_{\text {flow area }} .
$$

The pressure drop due to density change was calculated by Eq. (3.4) taken from Ref. 7:

$$
\Delta P_{\text {density }}=\frac{G^{2}}{g_{c}}\left(\frac{1}{\rho_{2}}-\frac{1}{\rho_{1}}\right),
$$

where the subscripts $\underline{1}$ and $\underline{2}$ refer to the entrance and exit, respectively, of the region considered. Slight changes in channel flow area were caused by diametral ( $<0.004$ in.) shrinkage of the flow shroud at the pressure taps during fabrication. The corresponding pressure drops were calculated as follows from Ref. 7:

$$
\Delta P_{\text {flow area }}=\frac{G^{2}}{2 g_{C} \rho}\left[1-\left(A_{1} / A_{2}\right)^{2}\right]
$$

where $A_{1}$ and $A_{2}$ are the cross-sectional areas preceding and following the area change.

The Blasius friction factor was determined from:

$$
f=\frac{2 g_{C} D_{h}}{\dot{\nu}_{I} \bar{V}^{2}\left(Y_{U_{C}}-Y_{u_{1}}\right)} \Delta P_{\text {friction }}
$$

Here $\bar{V}$ is the average gas bulk velocity in the segment under consideration and $\mathrm{X}$ is the axial position along the heater rod where the subscripts $\underline{I}$ and $\underline{2}$ correspond to the entrance and exit of a segment. Following the recommendations of Ref. \&, the gas properties entering into the friction factor $f$ and the modified Reynolds modulus $R_{I}$ were evaluated at an effective temperature $\mathrm{T}_{\mathrm{I}}$ given by:

$$
T_{I}=B\left(T_{W} \cdots T_{b}\right)+T_{b}
$$

The value of $B=0.05$ was selected by trial and error to remove data scatter resulting from temperature dependent gas property variations. 


\subsection{Transformations}

The measurements obtained in these tests reflect the influence of both the rod surface and the shroud surface. Thus, for example, increasing the roughness of the rod surface would improve the measured heat transfer coefficient while the friction factor would increase a relatively small amount since the character of most of the wetted perimeters, namely the shroud surface, has not changed. Consequently, it would be incorrect to apply the average heat transfer coefficients and friction factors obtained from an annulus experiment to a bundle type reactor fuel element in which most of the surface would be roughened, and it becomes necessary to separate the contributions from the component surfaces. In recent years, most of the methods to accomplish this separation have relied on the principle of a transformation due to Hall. ${ }^{9}$ These methods have made use of a surface of zero shear for separating the properties of the rough and the smooth surfaces, but they differ in the method for locating it. With the present state of knowledge, experimental measurements are required to locate the zero-shear surface precisely; however, these measurements are difficult to perform, and a number of simplified methods have been used to estimate the surface's position.

In the present study a Hall-type transformation recommended by Markóczy $y^{10}$ on the basis of experimental verification in Ref. 11 was used to remove the effect of the shroud surface upon the Stanton modulus and the friction factors of the rod heaters. Additionally, this particular transformation should allow direct comparison in the future with heat transter tests on similar surfaces underway at the Eidg. Institut für Reaktorforschung in Würenlingen, Switzerland. In the transformation, the annulus is assumed to consist of two concentric f'low regions separated by an adiabatic zero-shear surface, as depicted in Fig. 3.1. Below are listed some of the assumptions used in the development of the friction factor and Stanton modulus transformations.

1. The axial pressure drop is unifurm in the flow regions.

2. The surface heat flux is uniform and the fluid temperature profiles are fully developed, thus $\partial \mathrm{T} / \partial \mathrm{X}$ is constant.

3. The fluid properties are independent of radial position. 


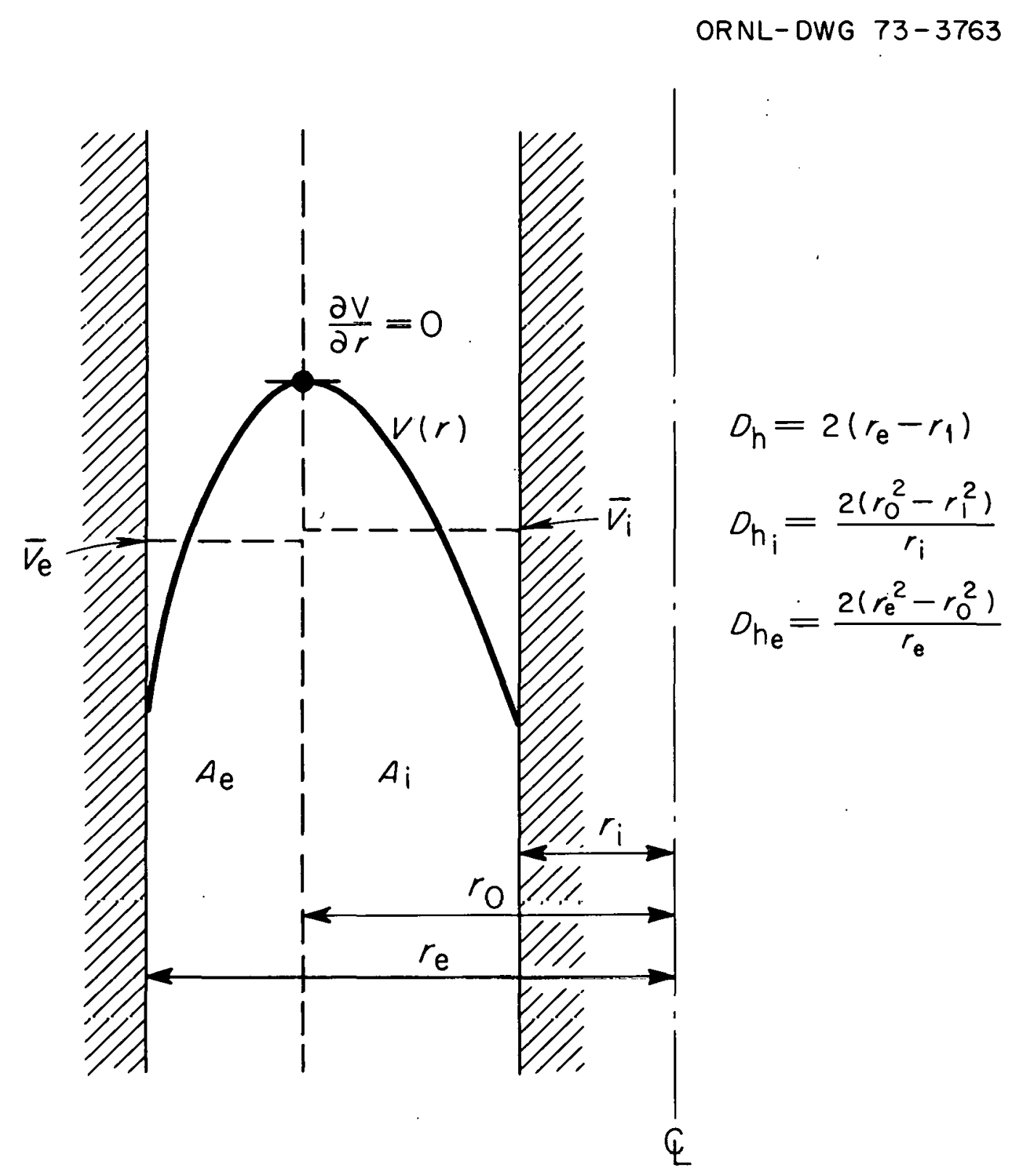

Fig. 3.1. Annulus flow channel diagram. 
4. The effective conductivity, $K$, of the gas in the turbulent region is independent of the radial temperature distribution.

5. The surfaces of zero shear and maximum velocity coincide. This ignores radial velocity components that are probably minor.

6. The rod surface heat flux $\dot{q}$ is identical for the experimental and transformed cases, thus, $\dot{q}=\dot{q}_{i}$.

7. For the transformed case there is no momentum or heat transport across the surface of zero shear.

8. There is no interaction between the velocity and the temperature aistribution.

9. The average velocities in the inner and the juter channel are the same, thus $\tilde{V}_{i}=\bar{V}_{e}=\bar{V}$.

The actual test conditions probably do not satisfy the stipulated physical conditions. However, this does not detract from the usefulness of the approach, since it leads to relatively simple analytical solutions to complex problems, providing a convenient method for correlating and applying a variety of experimental data on rod-type heat transfer surfaces.

\subsubsection{Friction Factor Transformation}

The subscript $\underline{i}$ has been used to identify the inner channel while $\underline{e}$ designates the outer channel; nonsubscripted symbols refer to the entire flow area. Under the tirst assumption:

$$
\frac{\partial P}{\partial X}=\frac{\partial P_{i}}{\partial X}=\frac{\partial P_{e}}{\partial X}
$$

Thus, under As sumptions (3) and (9) one obtains:

$$
\frac{f_{1}}{r}-\frac{D_{h i}}{D_{h}}
$$

and

$$
\frac{f_{e}}{f}=\frac{D_{h e}}{D_{h}} .
$$


As indicated in Fig. 3.1, the hydraulic diameters of the various flow channels are given by the expressions:

$$
D_{h}=2\left(r_{e}-r_{0}\right) ; \quad D_{h_{i}}=\frac{2\left(r_{0}^{2}-r_{i}^{2}\right)}{r_{i}} ; \quad D_{h_{e}}=\frac{2\left(r_{e}^{2}-r_{0}^{2}\right)}{r_{e}} .
$$

Defining :

$$
D_{h} \equiv \frac{4 A}{p} ; \quad D_{h_{i}} \equiv \frac{4 A_{i}}{p_{i}} ; \quad D_{h_{p}} \equiv \frac{4 A}{p_{e}}
$$

and

$$
A^{*} \equiv \frac{A}{A} ; \quad p^{*} \equiv \frac{P}{p},
$$

one can obtain from Eqs. (3.9) and (3.10):

$$
\frac{f_{i}}{f}=\frac{1-A^{*}}{I-p^{*}} ; \quad \frac{f}{f}=\frac{A^{*}}{p^{*}} .
$$

From the definition of the Reynolds modulus and Assumptions (3) and (9), it follows that:

$$
\frac{R c_{i}}{R e}=\frac{D_{h i}}{D_{h}} ; \quad \frac{R o_{e}}{R e}=\frac{D_{h e}}{D_{h}} .
$$

Substituting Eqs. (3.9) and (3.10), respectively, one obtains:

$$
\frac{\operatorname{Re}_{i}}{\operatorname{Re}}=\frac{f_{i}}{f} \text { and } \frac{\operatorname{Re}_{e}}{\operatorname{Re}}=\frac{f_{e}}{f} .
$$

Assuming that the friction factor of the smooth outer channel can be represented by:

$$
\mathrm{f}_{\mathrm{e}}=\mathrm{C} \operatorname{Re}_{\mathrm{e}}^{\mathrm{n}} \text {, }
$$

and taking Eq. (3.13) into account it follows that: 


$$
f=C \operatorname{Re}_{e}^{n} \frac{p^{*}}{A^{*}},
$$

and

$$
\frac{\operatorname{Re}_{e}}{\operatorname{Re}}=\frac{f_{e}}{f}=\frac{A^{*}}{p^{*}} .
$$

Letting $f_{s}$ be the friction factor for the entire flow channel with smooth surfaces at a Reynolds modulus of Re, one obtains

$$
\frac{f}{f_{S}}=\frac{C \operatorname{Re}_{e}^{n} n^{*}}{C \operatorname{Re}^{n} A^{*}} .
$$

Substituting Eq. (3.18), it follows that:

$$
\frac{f}{f_{s}}=\left(\frac{A^{*}}{p^{*}}\right)^{n-1},
$$

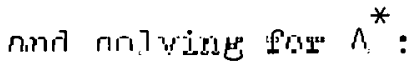

$$
A^{*}=p^{*}\left(\frac{f}{f_{s}}\right)^{1 /(n-l)}
$$

Combining Eqs. (3.13) and (3.21) one obtains:

$$
\frac{ \pm_{i}}{f}-\frac{1-p^{*}\left(t^{\prime} / \pm_{S}\right)^{1 /\left(1 n^{-1}\right)}}{1-p^{*}} .
$$

Here $t_{i}$ is the friction factor for a rod surface surrounded by a flow annulus, which in turn is bounded by a zero-shear surface at $r_{\circ}$. In principle these values no longer reflect the influence of the outer wall of the test annulus, thus allowing comparison with and application to other flow geometries that have been similarly transformed.

If the friction factor, $f_{S}$, is known, the position of the surface of zero shear can be computed from (3.21): 


$$
r_{0}=\sqrt{r_{e}^{2}-\left(r_{e}-r_{i}\right) r_{e}\left(f / f_{s}\right)^{l /(n-1)}} \text {. }
$$

For smooth surfaces this reduces to:

$$
r_{0}=\sqrt{r_{i} r_{e}} \text {. }
$$

\subsubsection{Stanton Modulus Transformation}

3.3.2.1 Hall-Type Transformation. The ratio of the Stanton modulus transformed for a rod, $S t_{i}$, to that observed for tests with annular geometry, st, is given by: ${ }^{11}$

$$
\frac{S t_{i}}{S t}=\frac{\frac{\left(T_{w}-T_{b}\right) k f_{i} \bar{v}}{8 v \dot{q}}}{\left(\frac{\Delta \bar{T} k f_{i} \bar{v}}{8 v \dot{q}}-1\right) \frac{\phi\left(r_{e} / r_{i}\right)}{\phi\left(r_{o} / r_{i}\right)}+1} \text {, }
$$

where

$$
\phi\left(r_{e} / r_{i}\right)=\frac{\left[\left(r_{e} / r_{i}\right)^{2}-1\right]^{2}}{\left(r_{e} / r_{i}\right)^{4}\left[d_{0 \prime \prime}\left(1_{e} / r_{i}\right)-3\right]+4\left(r_{e} / r_{i}\right)^{2}-1}
$$

and

$$
\phi\left(r_{0} / r_{i}\right)=\frac{\left[\left(r_{0} / r_{i}\right)^{2}-1\right]^{2}}{\left(r_{0} / r_{i}\right)^{4}\left[4 \operatorname{len}\left(r_{0} / r_{i}\right)-3\right]+4\left(r_{0} / r_{i}\right)^{2}-1} .
$$

The radius $r_{0}$ of the zero-shear surface in Eq. (3.25) was obtained from Eqs. (3.23) and (3.24). The rod surface heat flux, the effective turbulent conductivity of the gas, and the average gas flow velocities are the same for the transformed and experimental case in accordance with Assumptions 6, 8, and 9. The velocity was assumed constant across the flow channel except in the sublayer at the wall. 
3.3.2.2 Wilkie's Transformation. An alternative transformation for the Stanton modulus is one recommended by Wilkie 2 for square and other rib profiles:

$$
\frac{S t_{i}}{S t}=1.61-0.8 \mathrm{~A}_{i} / \mathrm{A}
$$

Here $A_{i}$ is the cross-sectional flow area between the rod surface and the zero-shear diameter $D_{0}$. In the present analysis, $D_{0}$ was obtained from Eq. (3.23). Equation (3.28) is an empirical relationship based on over 200 experimental points, and it applies to annuli with a smooth to rough perimeter ratio of about 2 , to gases with $\operatorname{Pr}=0.7$, and $\mathrm{T}_{\mathrm{w}} / \mathrm{T}_{0}$ between 1.19 and 1.25. Equation (3.28) was therefore judged applicable to the subject tests.

\section{RESULTS AND DISCUSSION

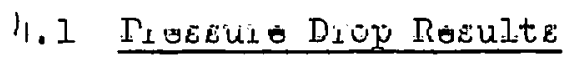

Before entering the test annulus, the coolant gas traverses a 45diam-long unheated entrance region, sufficient ${ }^{13}$ for the velocity profile to approach full development. The pressure drop measurements within the heated length were made at points beyond the rod centering spacers, at least 40 diameters into the heated region. Entrance length data for the t'low of air in tubes ${ }^{1}$ suggests this to be adequate to establish thermally and hydrodynamically developed flow. This expectation was confirmed by local friction factors, which were observed to be generally uniform. Pressure drop results for isothermal and heated tests are shown in terms of the annulus friction factor f, Eq. (3.6), in Fig. 4.1. Use of Eq. (3.7) to determine the gas properties removed data scatter due to temperature dependent properties. Also depicted is a friction factor relationship recommended by Knudsen and Katz ${ }^{15}$ for smooth annuli:

$$
f^{\prime}=0.2052 \mathrm{Re}^{-0.2},
$$


showing reasonably good agreement. EIR $^{16}$ results obtained with air at low pressure for $r_{e} / r_{i}=2.09$ at relatively low Re values agree quite well. The present results for a smooth annulus are well represented by:

$$
f=0.118 \operatorname{Re}^{-0.155}
$$

The largest friction factors were obtained for the surface with ring-type ribs while the rod with helical ribs gave values about midway between smooth and ring-type rib results. It can be seen in Fig. 4.1, that as the effective surface roughness increases, the friction factors show diminished dependence on the Reynolds modulus. This behavior is consistent with that observed for flows inside of roughened tubes. ${ }^{17}$

Figure 4.2 depicts the isothermal and the heated rod friction factors $f_{i}$, as calculated by Eq. (3.6) and transformed by Eq. (3.22) to remove the effect of the annulus outer wall. Good agreement with Wilkie's isothermal data ${ }^{18}$ for smooth rods is apparent in Fig. 4.2. It will be noted that rod friction factors exceed the annulus friction factors of Fig. 4.1 by about 50\% for the helical ribs and $90 \%$ f'or the transverse ribs, indicating that in this instance, the transformation had a significant effect on the magnitude of the roughened rod friction factors. Friction factors for the annulus with only smooth surfaces were not chldryed by lie trangformation oinos in this instianne $f_{1} / f=1.0$ per Eq. (3.22).

At a Reynolds modulus of 100,000 the friction factors for the helical- and ring-ribbed rods exceeded the smooth rod values by about 115 and $260 \%$ respectively. The roughened rod friction factors showed less dependence on the Reynolds modulus than the corresponding annulus values; this is to be expected since the rod values apply to surfaces roughened over their entire area and thus characterized by an increased average roughness. 


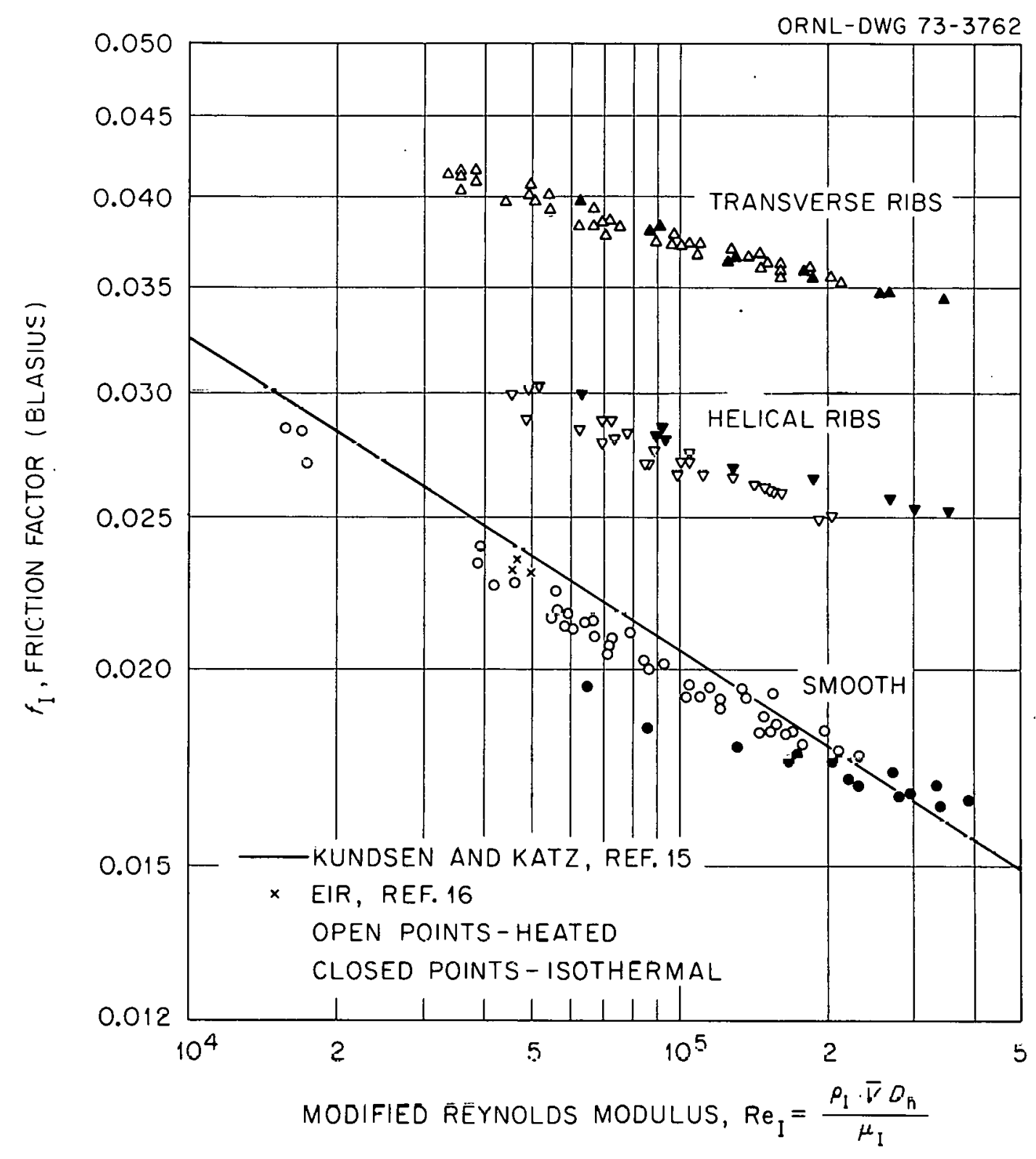

Fig. 4.1. Annulus friction factors. 


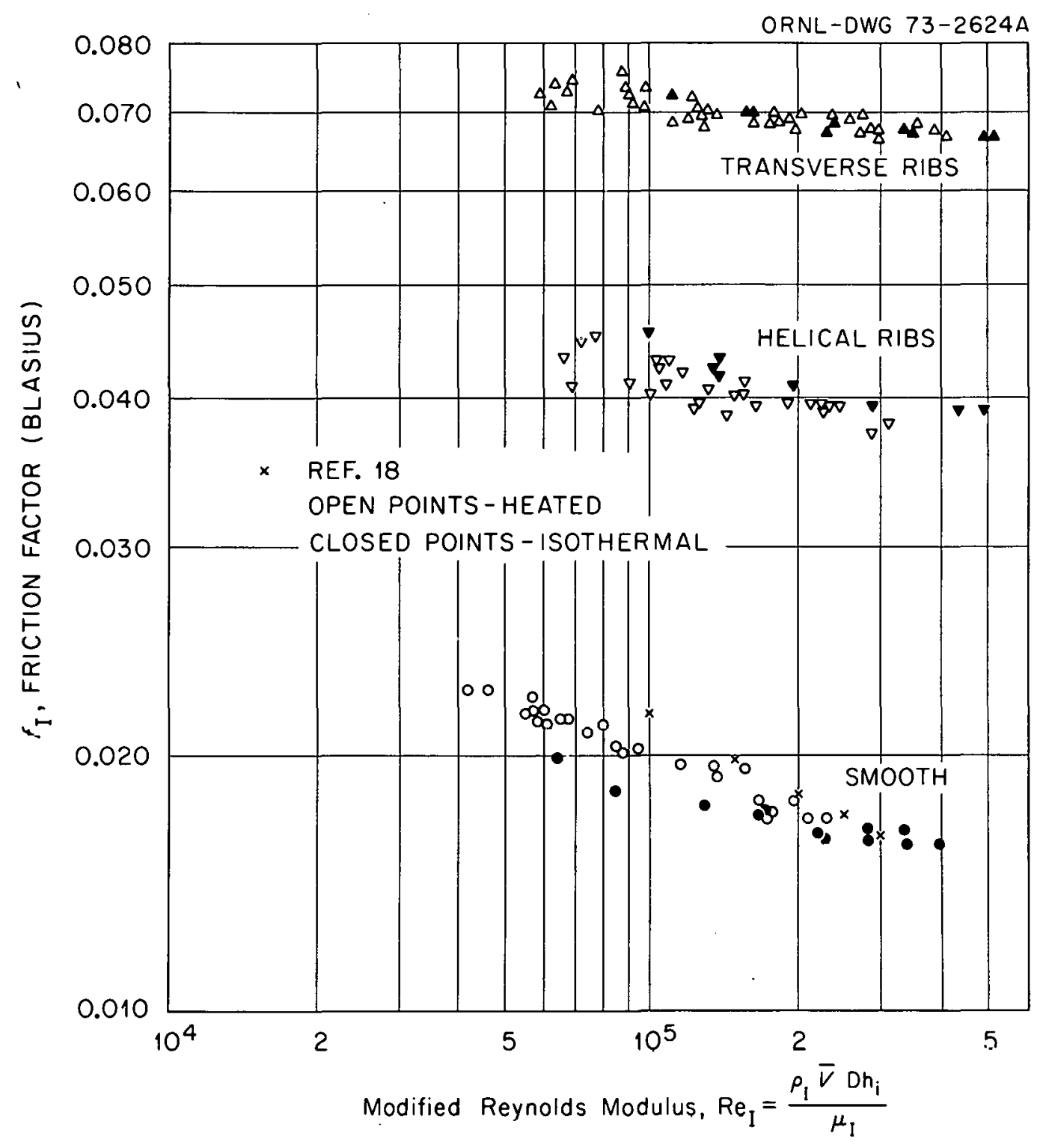

Fig. 4.2. Rod friction factors. 


\subsection{Heat Transfer Results}

The heater rod temperatures were measured in a region extending from 40 to 80 diameters into the heated length. The heat transfer results presented are based on the average temperature of a 3-in.-long segment extending from 18 to 21 in. (60 to 70 hydraulic diameters) from the start of the heated length. The total entrance length was 113 hydraulic diameters (of which 45 diameters were unheated) sufficient according to smooth. tube flow data ${ }^{4}$ to establish a fully developed temperature profile. This was validated by heat transfer measurements extending from 40 to 70 hydraulic diameters into the heated length, which showed an approach to uniform heat transfer coefficient values.

Annulus Stanton moduli for the three test surfaces are depicted in Fig. 4.3 plotted against the bulk Reynolds modulus; also shown are Kays $^{10}$ results for smooth annuli that lie about $20 \%$ above the present smooth surface data. EIR's smooth surface results ${ }^{16}$ for $\operatorname{Re}<50,000$ lie about $35 \%$ above the present results. Figure 4.4 shows the results transformed by Eq. (3.25) into rod geometry. Also depicted are some of Wilkie's ${ }^{18}$ results for gaseous heat transfer. The solid line, representing his stanton moduli for transverse ribs with a pitch to height ratio of 12 and a height to equivalent diameter ratio of 0.0106 (matching. the subject test parameters), lies about $25 \%$ above the present results. Good agreement with Wilkie's smooth rod results (the dashed line in Fig. 4.4) is evident.

Tine data scatter of Figs. 4.3 and 4.4 was diminished considerably when those results were expressed in terms of $\phi(\mathrm{st})$, Figs. 4.5 and 4.6 where :

$$
\phi(\text { St })=3 t \operatorname{Pr}^{0.6}\left(\mathrm{~T}_{\mathrm{w}} / \mathrm{T}_{\mathrm{b}}\right)^{\mathrm{n}}
$$

This form follows the recommendation of Kays; ${ }^{20}$ a value of $n=0.1$ limited the annulus data scatter due to temperature dependent property variations to a range of about $\pm 5 \%$, compared to about $\pm 10 \%$ for the Stanton modulus values. Data consistency was even better for the rod results, which show a scatter of only about $4 \%$ in Fig. 4.6 for ratios of wall-to-gas temperature ranging up to 2.4, and Reynolds moduli from about 


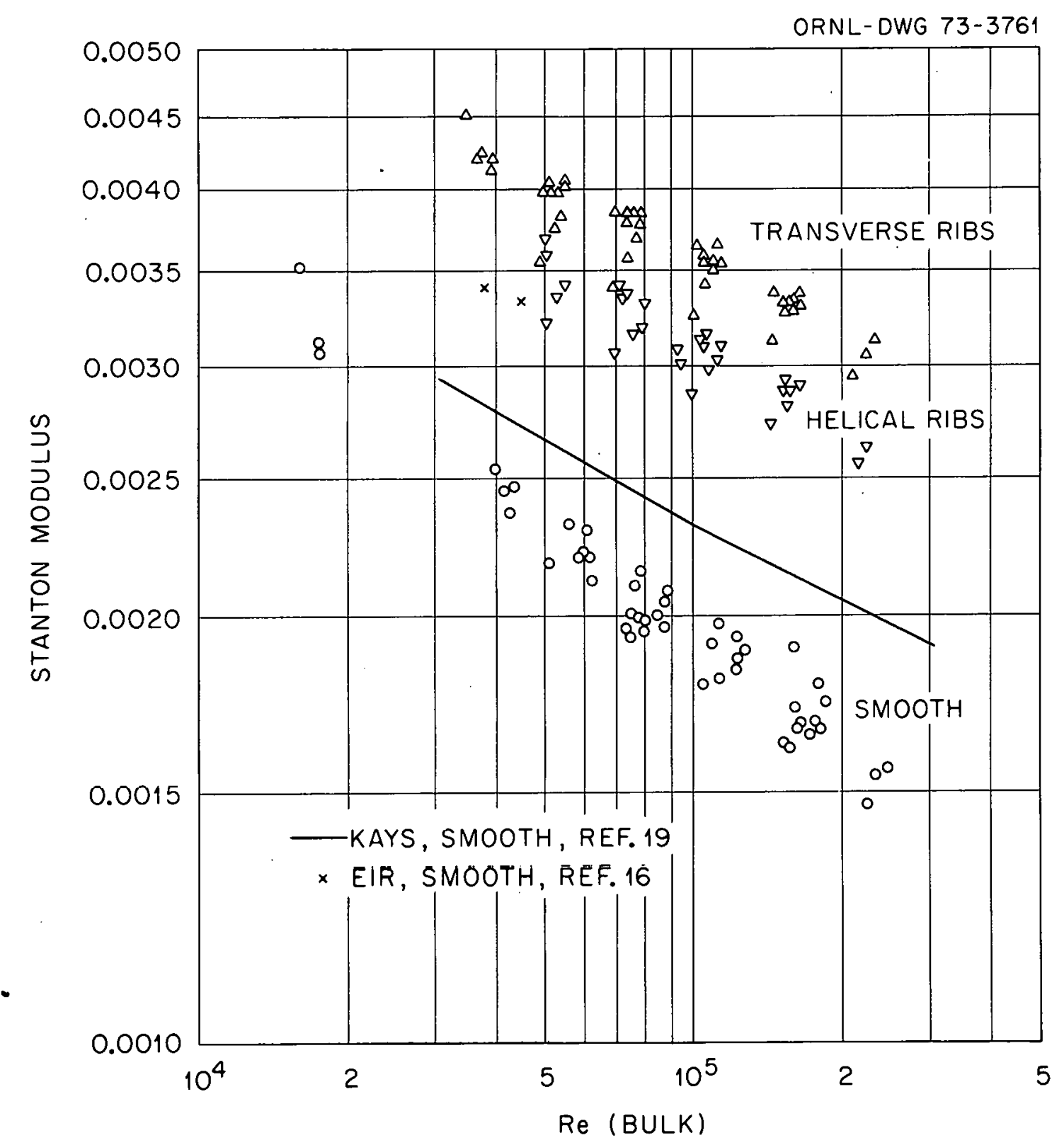

Fig. 4.3. Annulus Stanton modulus. 


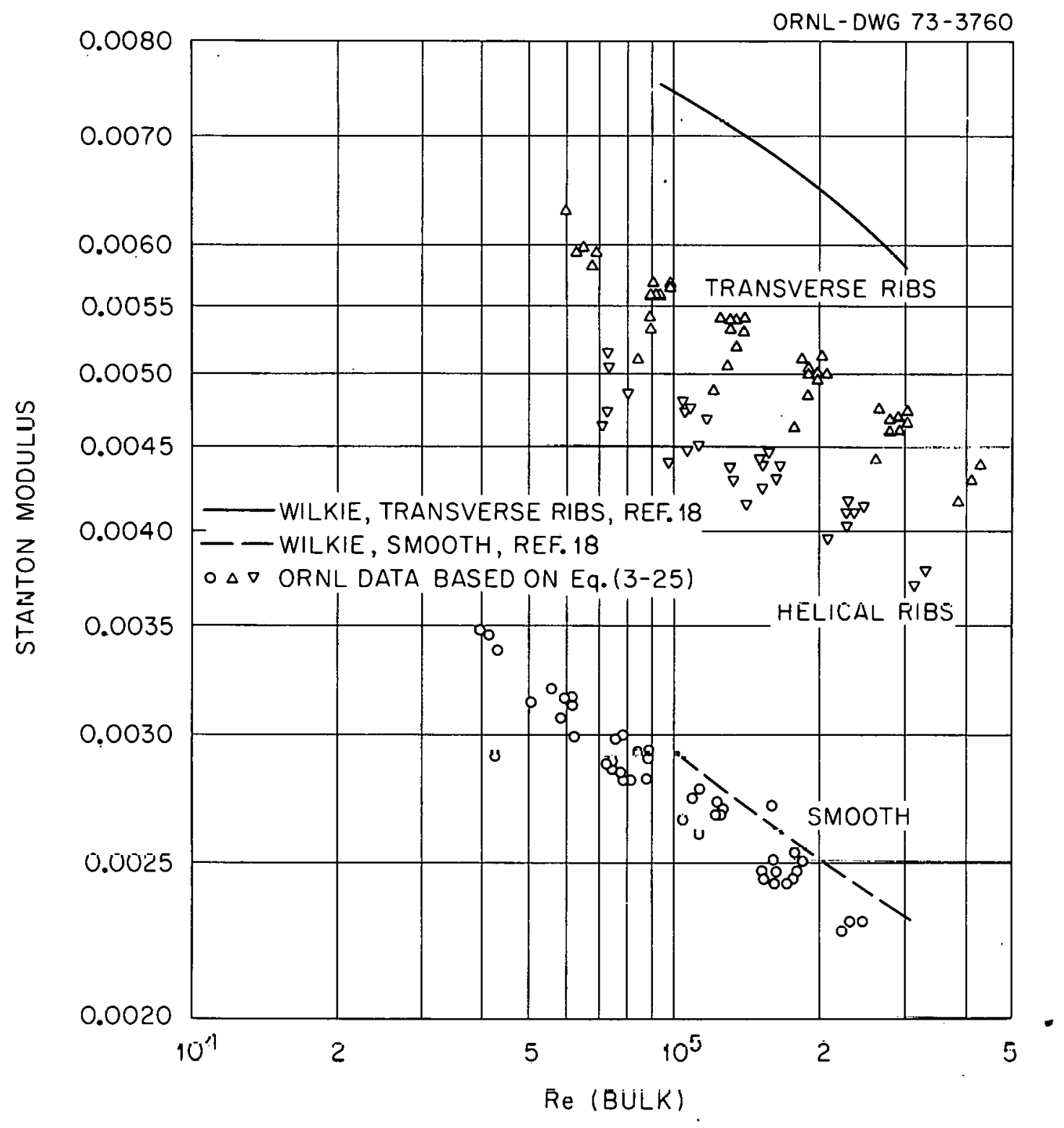

Fig. 4.4. Rod Stanton modulus. 


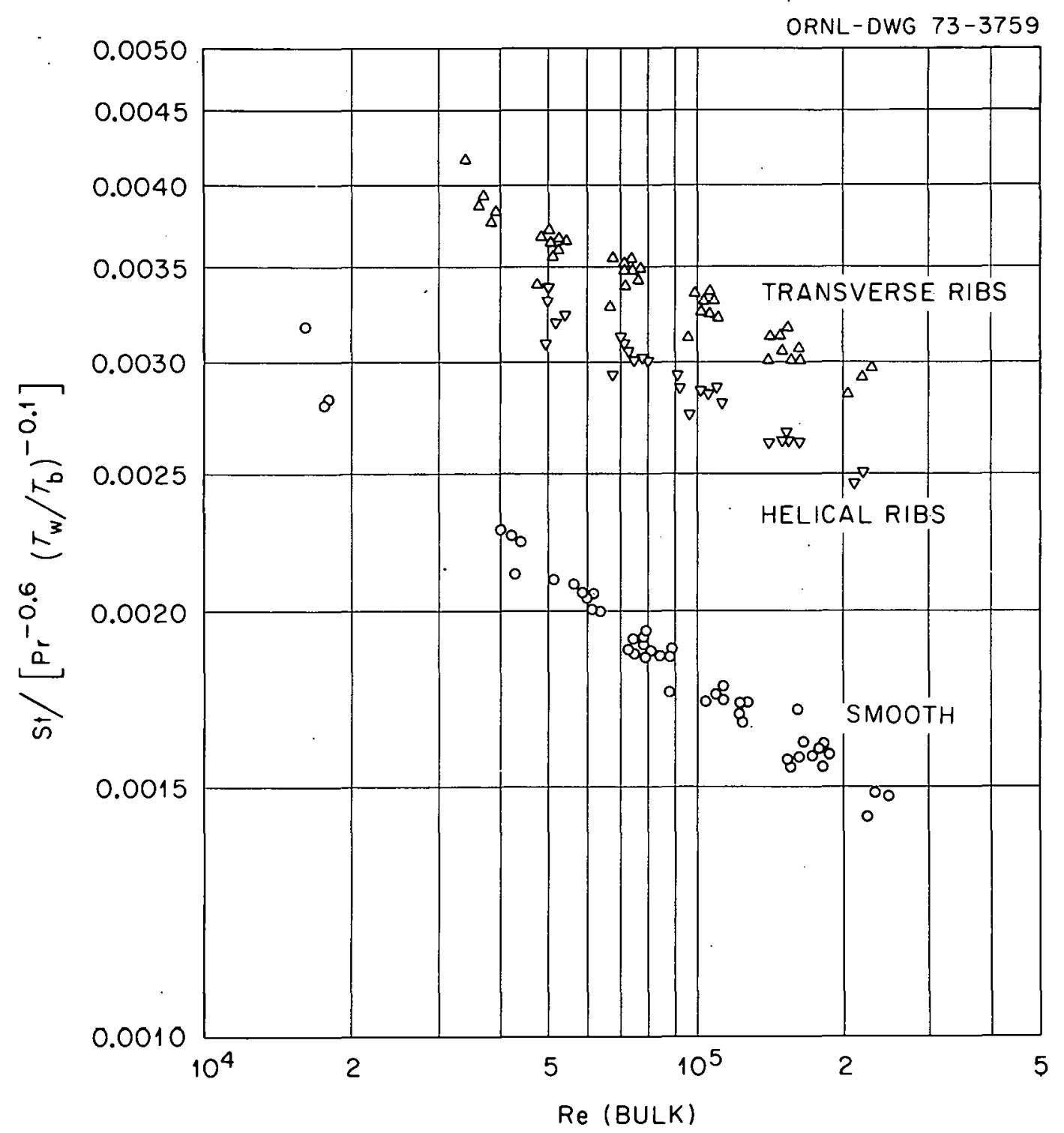

Fig. 4.5. $\emptyset(S t)$ - annulus. 


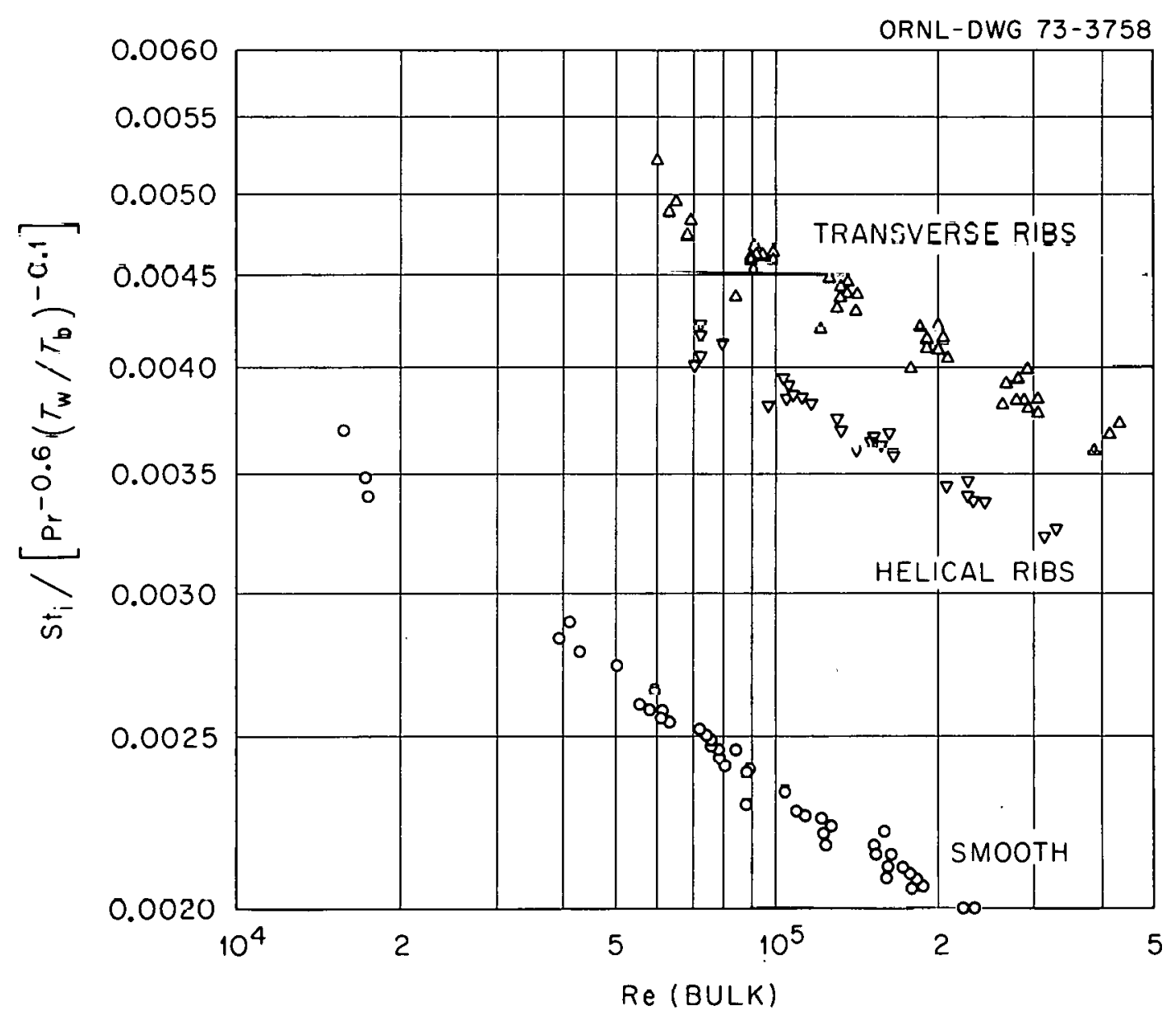

Fig. 4.6. $\varnothing\left(S t_{i}\right)$ - rod, transformation Eq. (3.25). 
16,000 to 450,000. Relative to a smooth surface at constant Reynolds modulus, the heat transfer coefficient of the transversely ribbed rod was from 92 to $102 \%$ better in the Reynolds modulus range from 60,000 to 300,000. The corresponding improvement for the spiral ribs ranged from 63 to $71 \%$.

The sensitivity of the roughened rod heat transfer results to the transformation method employed is apparent in Fig. 4.7, which is based on Wilkie's ${ }^{2}$ transformation, Eq. (3.28). It will be noted that the performance of the smooth and of the spirally ribbed rods differs little from that obtained with the Hall-type ${ }^{10}$ transformation, Fig. 4.6; however, the transverse ribs, Fig. 4.7, showed $\phi(S t)$ values about $10 \%$ lower than were obtained with the Hall-type transformation. Relative to a smooth surface at constant Reynolds modulus, the transversely ribbed rod showed a superiority of 68 to $86 \%$ over Reynolds modulus values between 60,000 and 300,000 . The corresponding values for the spiral ribs were 54 to $67 \%$.

\subsection{Comparison with Other Results}

A comparison was made with some of EIR's preliminary heat transfer and pressure drop results ${ }^{21}$ for photoetched spiral and transverse ribs that were tested using air at about two atmospheres. Also included were some of Wilkie's data for gaseous heat transfer with rectangular transverse ribs. The characteristics of the various surfaces are listed in Table 4.1, showing that the ratio of rib height to rod diameter for the EIR tests was about $14 \%$ smaller than for the ORNL tests; other minor discrepancies involve the ratio of rib height to width and the ratio of rodto-shroud diameter.

The test results are summarized in Fig. 4.8 in terins of $f_{i} / f_{i \text { smooth }}$

plotted against $S t_{i} / S t_{i}$ smooth for a Re value of 100,000 . The EIR values are also based on the transformation expressed in Eq. (3.25); however, their transverse rib results show slightly better heat transfer performance than the corresponding present test results. EIR's spiral rib performance, on the other hand, approaches that of the current tests. Use of Wilkie's Eq. (3.28) to transform the ORNL results reduces the stanton 


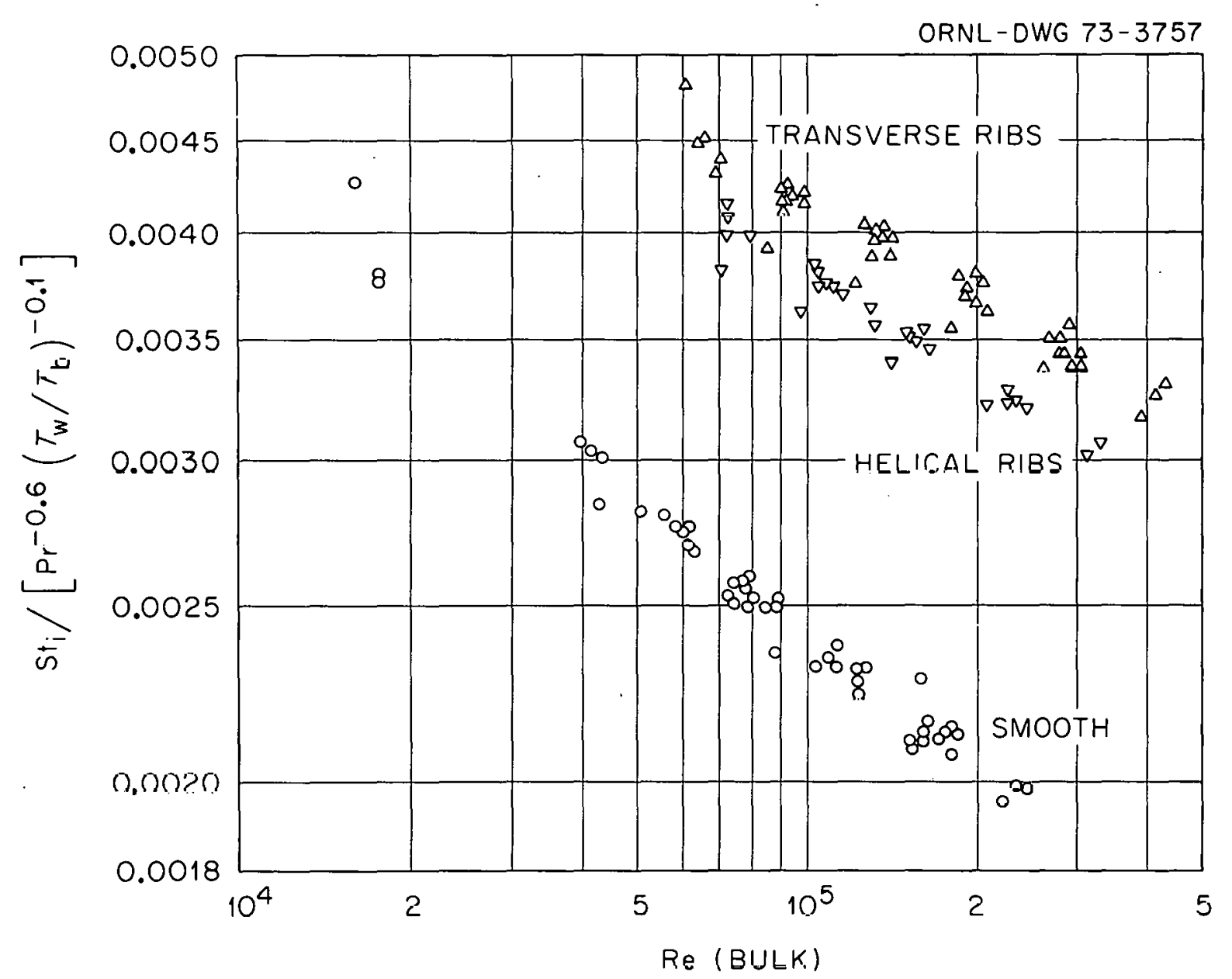

Fig. 4.7. $\emptyset\left(S t_{i}\right)$ - rod, transformation Eq. (3.28). 
Table 4.1. Characteristics of Rod Roughnesses

\begin{tabular}{|c|c|c|c|c|c|c|c|c|c|}
\hline \multirow{2}{*}{ Identification } & \multirow{2}{*}{ Trpe } & \multirow{2}{*}{$\begin{array}{r}\text { Bod or } \\
\text { (in.) }\end{array}$} & \multirow{2}{*}{$\begin{array}{l}\text { Rib Heĩght } \\
\text { (in.) }\end{array}$} & \multirow{2}{*}{$\begin{array}{l}\text { Rib Width } \\
\text { (in.) }\end{array}$} & \multirow{2}{*}{$\begin{array}{l}\text { Pitch } \\
\text { (in.) }\end{array}$} & \multirow{2}{*}{$\frac{\text { Rib Pitch }}{\text { Rib Height }}$} & \multirow{2}{*}{$\frac{\text { Rib Width }}{\text { Rib Height }}$} & \multirow{2}{*}{$\frac{\text { Rib Height }}{\text { OD }}$} & \multirow{2}{*}{$r_{e} / r_{i}$} \\
\hline & & & & & & & & & \\
\hline EIR :Ref. 2l) & $\begin{array}{l}\text { Spiral ribs } \\
34 \mathrm{deg} \text { helix }\end{array}$ & 0.338 & 0.006 & 0.014 & 0.072 & 12.0 & 2.3 & 0.018 & $\begin{array}{l}1.63,2.09, \\
\text { and } 2.56\end{array}$ \\
\hline EIR :Ref. 21) & Transverse ribs & 0.338 & 0.006 & 0.018 & 0.072 & 12.0 & 3.0 & 0.018 & $\begin{array}{c}1.63,2.09 \text {, } \\
\text { and } 2.56\end{array}$ \\
\hline Presənt results & Spiral ribs & 0.289 & 0.0 .56 & 0.012 & 0.072 & 12.0 & 2.0 & 0.0208 & 2.07 \\
\hline Pres ent results & Transverse ribs & 0.288 & 0.0056 & 0.012 & 0.072 & 12.0 & 2.0 & 0.0208 & 2.07 \\
\hline Wilkie (Ref. 18) & Transverse ribs & 1.87 & & & & 12.0 & & & 1.91 \\
\hline
\end{tabular}


O SPIRAL RIBS, REF. 21

ORNL-DWG 73-3756

- SPIRAL RIBS, ORNL, TRANSFORMATION EQ. 3-25

- SPIRAL RIBS, ORNL, TRANSFORMATION EQ. 3-28

- TRANSVERSE RIBS, REF. 21

- TRANSVERSE RIBS, ORNL, TRANSFORMATION EQ. 3-25

- TRANSVERSE RIBS, ORNL, TRANSFORMATION EQ. 3-28

- TRANSVERSE RIBS, REF. 18

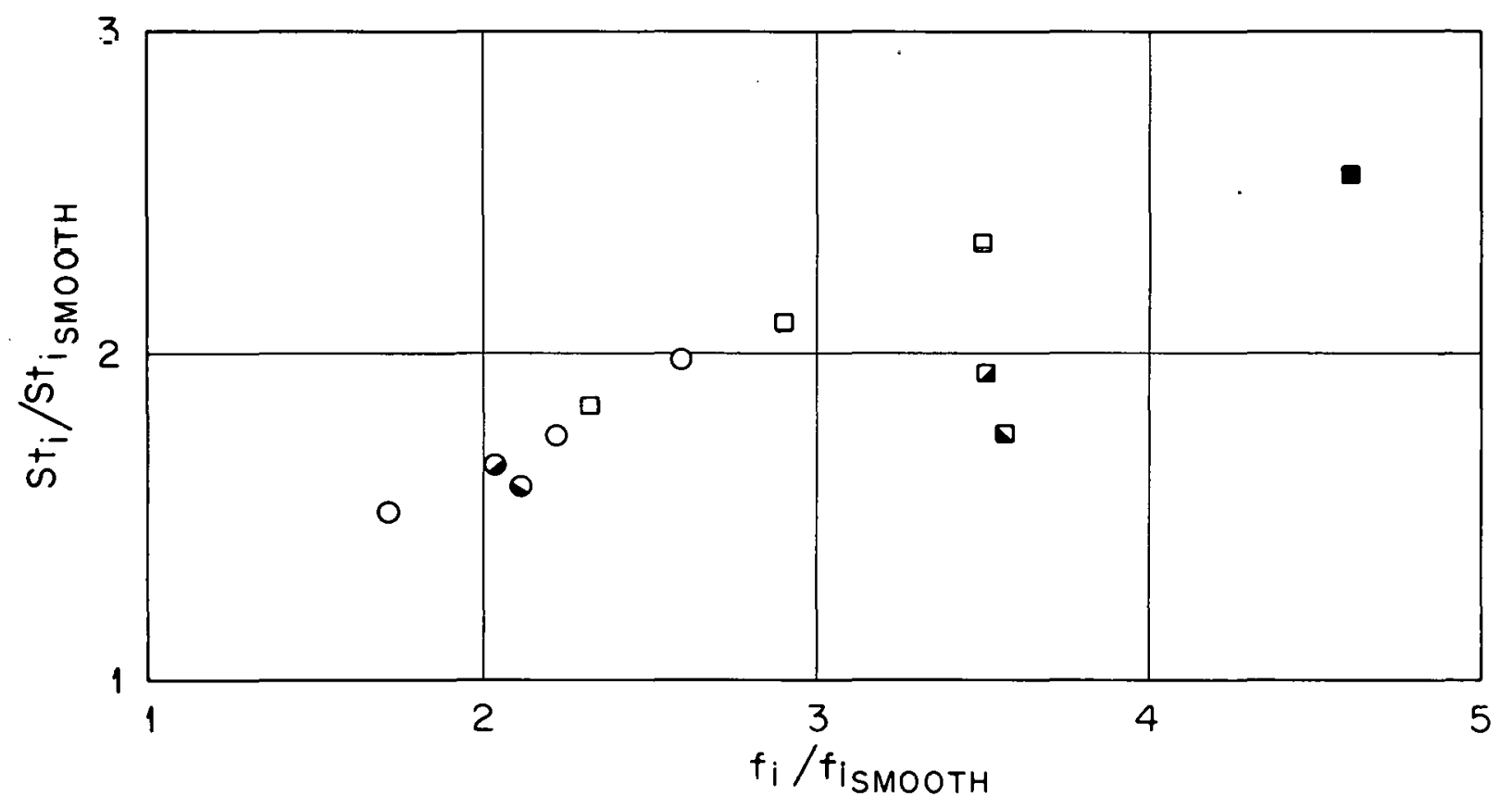

Fig. 4.8. Comparison with other data at $R e=1 n n, \cap \cap n$. 
moduli for the transverse ribs by about $9 \%$ below values based on the Halltype transformation, placing the performance of this surface about $20 \%$ below the EIR results. Wilkie's ${ }^{18}$ result for square ribs obtained using a Hall-type transformation based on actual velocity and temperature distribution measurements appears consistent with EIR's data extrapolated to higher $f_{i} / f_{i}$ smooth values.

There are a number of factors that may have contributed to the discrepancies between the various experiments. The contours produced by photoetching are difficult to define precisely because the resulting ribs are not strictly rectangular and thus close matching of the EIR and ORNL results to Wilkie's data for rectangular ribs is not to be expected. Slight differences in rib shape or the surface finish of the heater rod on the flow shroud, or perhaps variances in the experimental conditions, may have contributed to the discrepancies between EIR and ORNL results. Additional uncertainties introduced by the transformations employed in data analysis are difficult to assess from the limited number of test geometries used in the present tests.

In summary, it appears that the subject tests are reasonably consistent with EIR's preliminary results; further, the tests provide useful data on the relative performance of the two roughnesses examined. In terins of the pressure drop and heat.transfer parameters of Fig. 4.8, the heat transfer performance of transverse ribs is somewhat poorer than suggested by previous results. 21

\section{SURFACE EFFECTIVENESS}

The performance evaluation of enhanced heat transfer surfaces should consider the heat transfer capability as well as the flow resistance of a particular design. A performance criterion suggested by Bergles ${ }^{22}$ compares the heat transfer coefficient at a given pumping power for an enhanced surface to that of a smooth surface requiring the same pumping power. In the present comparison, it was assumed that the hydraulic diameter, and the average fluid and wall temperatures were identical for the enhanced and the smooth rod. The experimental friction factors and 
heat transfer coefficients were transformed to rod geometry by the methods described in Chapter 3.

The effectiveness $\mathrm{E}$ can be written as:

$$
E=\frac{h_{i}}{h_{i} \text { smooth }} \text {, at constant pumping power }
$$

If $\mathrm{E}$ is greater than 1.0 the surface is attractive. The pumping power requirements for the roughened rods were based on the experimentally determined friction factors. For the hypothetical smooth rod in the comparison, a flow rate was chosen that required the identical pumping power. Friction factors for the smooth rod were obtained from Eq. (4.2). The results shown in Table 5.1 indicate that the transformation methods used in the analysis have some influence on the magnitude of $E$, particularly for transversely ribbed rods; the Hall-type transformation consistently resulted in an effectiveness higher than that obtained with Wilkie's transformation. On an overall basis, and bearing in mind the

Table 5.1. Surface Effectiveness

\begin{tabular}{lllllll}
\hline Re $\times 10^{3}$ & 60 & 100 & 200 & 300 & 400 \\
\hline & $\begin{array}{c}\text { Transformation } \\
\text { Eq. (3.25) }\end{array}$ & 1.36 & 1.38 & 1.41 & 1.43 & \\
$\begin{array}{c}\text { Effectiveness } \\
\text { spiral ribs }\end{array}$ & $\begin{array}{c}\text { Transformation } \\
\text { Eq. (3.28) }\end{array}$ & 1.30 & 1.37 & 1.33 & 1.36 & \\
$\begin{array}{c}\text { Trfectiveness } \\
\text { transverse } \\
\text { ribs }\end{array}$ & $\begin{array}{c}\text { Eq. (3.25) } \\
\text { Transformation } \\
\text { Eq. (3.28) }\end{array}$ & 1.36 & 1.39 & 1.40 & 1.42 & 1.43 \\
\hline
\end{tabular}

uncertainties in the results, it appears that the effectiveness of the spiral ribs equals that of the transverse ribs. Compared to smooth surfaces, the enhanced surfaces showed that performance improved by 18 to 
$43 \%$ at constant pumping power over the range of Reynolds moduli investigated. The influence of variation in Reynolds modulus on the effectiveness is minor, generally showing a slight increase in $E$ as Re rises from 60,000 to 400,000 .

\section{CONCLUSIONS}

The heat transfer and pressure drop results obtained with photoetched ribbed rods showed that relative to a smooth rod, helical ribs increased the heat transfer coefficient at $\operatorname{Re}=100,000$, in the range from 50 to $65 \%$, depending upon the data analysis method used. The corresponding improvements for transverse ribs ranged from 76 to $93 \%$. The associated friction factor increases amounted to 115 to $260 \%$, respectively, for the spiral and transversely ribbed surfaces. These conclusions are necessarily tentative because of uncertainties inherent in the methods employed to transform the annulus experimental results into a form applicable to rod surfaces. Greater confidence is held in the performance of the spiral ribs relative to that of the transverse ribs. The results indicate that in terms of an effectiveness $E$ at constant pumping power the two surfaces perform about equally well.

Reasonably good agreement was obtained with preliminary EIR $^{21}$ results at $\operatorname{Re}=100,000$ for somewhat similar photoetched rod surfaces when the same transformation was applied to both sets of data. Here the present results showed performance about equal to that cited in Ref. 21 for helical ribs and slightly poorer for the transverse ribs.

For application to multirod arrays, helical ribs may be preferred over transverse ribs, since the swirl flow induced by the former may promote interchannel mixing. 
REFERENCES

1. 0. H. Klepper, Heat Transfer Performance of Short Twisted Tapes,

A. I. Ch. E. Symposium Series, 69(13I), 87-93 (1973).

2. G. J. Kidd, Jr. and H. W. Hoffman, GCRP Semiannu. Progr. Kep., Sept. 30, 1968, ORNL-4353, pp. 129-39.

3. Letter from John B. Dee, Manager, GCFR Engineering Department, General Atomics Company, to Paul R. Kasten, Director, Gas-Cooled Reactor Program, Oak Ridge National Laboratory, Jan. 15, 1971.

4. Job Specification JS-25-245, Reactor Division, Oak Ridge National Lalur'ulur:y, Aug, 23, 1971,

5. D. R. Green, R. E. Collingham, and L. H. Fischer, Infrared NDT of Electrical Huel Hin SimuLator Used in LMFBR Thermal Hydraulic Tests, HEDL-TME-72-146, UC-79m (November 1972).

6. B. L. Pierce, 'the 'Thermodynamic and Transport Properties of Helium and Nitrogen, WANT-TME-1753 (1968).

7. W. M. Kays and A. I. London, Compact Heat Exchangers, 2nd Ed., p. 33, McGraw-Hill Book Company, New York, N. Y., 1954.

8. L. V. Humble, W. H. Lowdermilk, and L. G. Desmon, Measurements of Average Heat Transfcr and Friction Coefficients for Subsonic Flow of Air in Smooth Tubes at High Surface and Fluid Temperatures, NACA Report 1020, Lewis Flight Propulsion Laboratory (1951).

9. W. B. Hall, "Heat Transfer in Channels Having Rough and Smooth Surfaces," J. Mech. Hin. Bii., 4(3), $207-91$ (1950).

10. G. Markóczy, Konvective Wärmeübertragung In Längsangestromten RohrOder Stabsbündeln, Eidg. Institut für Reaktorforschung, TM-In-430, Appendix A (April 1970).

11. B. Kjellström, Influence of Surface Roughness on Heat Transfer and Pressure Drop in Turbulent Flow, AE-RTJ-821, Aktiebolaget Atomenerg, Stockholm, Sweden, 1966.

L'. D. Wilkie, "Calculation of Heat Transfer and Flnw Resistance of Rough and Smooth Surfaces Contained in a Single Passage," Proceedings of the Third International Heat Transfer Conference, A.I.Ch.E., Chicago, Illinois, August 1966.

13. J. G. Knudsen and D. L. Katz, Fluid Dynamics and Heat Transfer, p. 238, McGraw-Hill Book Company, New York, N. Y., 1958. 
13. J. G. Knudsen and D. L. Katz, Fluid Dynamics and Heat Transfer, p. 238, McGraw-Hill Book Company, New York, 1958.

14. W. M. Kays, Convective Heat and Mass Transfer, p. 190, McGraw-Hill Book Company, New York, 1966.

15. J. G. Knudsen and D. I. Katz, Fluid Dynamics and Heat Transfer, McGraw-Hill Book Company, New York, 1958.

16. M. Hudina, Rohan Tests, Preliminary Results, Eidg. Institut für Reaktorforschung, TM-IN-463 (February 1971).

17. J. G. Knudsen and D. I. Katz, Fluid Dynamics and Heat Transfer, p. 176, McGraw-Hill Book Company, New York, 1958.

18. D. Wilkie, "Forced Convection Heat Transfer from Surfaces Roughened by Transverse Ribs," Proceedings of the Third International Heat Transfer Conference, A.I.Ch.E., Chicago, Illinois, August 1966.

19. W. M. Kays, Convective Heat and Mass Transfer, Table 9-4, McGrawHill Book Company, New York, 1966.

20. W. M. Kays, Convective and Mass Transfer, p. 185, McGraw-Hill Book Company, New York, 1966.

21. Letter from G. Markóczy to O. H. Klepper, January 31, 1973.

22. A. E. Bergles, A. R. Blumenkrautz, and J. Taborek, "Performance Evaluation Criteria for Enhanced Heat Transfer Surfaces, "Paper No. 9, AIChE-ASME' 'Thirteenth National Heat Transfer Conference, Denver, Colorado, August 1972. 


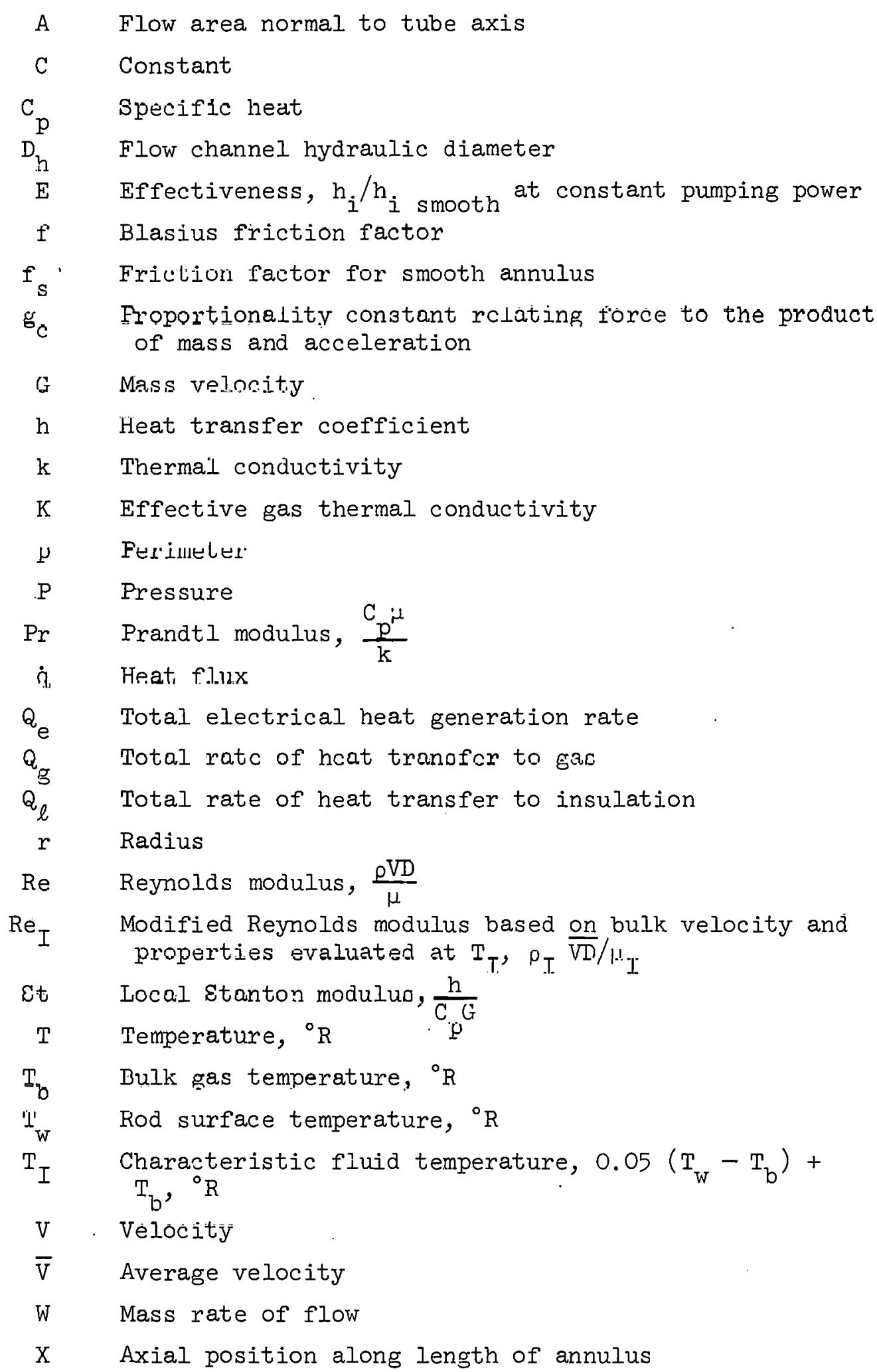


Greek Symbols

$\begin{aligned} & \delta \text { Thickness of laminar sublayer } \\ & \Delta H \text { Enthalpy rise } \\ & \Delta P \text { Pressure drop } \\ & \Delta T \text { Temperature drop } \\ & \epsilon_{H} \text { Turbulent diffusivity of heat } \\ & \nu \text { Kinemetic viscosity } \\ & \mu \text { Fluid viscosity } \\ & \mu_{I} \text { Fluid viscosity based on } \mathrm{T}_{\mathrm{I}} \\ & \rho \text { Bulk density based on } \mathrm{T}_{\mathrm{b}} \\ & \rho_{\mathrm{I}} \text { Bulk density based on } \mathrm{T}_{\mathrm{I}} \\ & \tau \text { Wall shear stress } \\ & \varnothing(\text { St) } \text { Nondimensional function of local Stanton modulus } \\ & \text { Subscripts }\end{aligned}$

$1 \quad$ Entrance

2 Exit

i Inner flow channel

e Outer flow channel

- Zero shear surface

$s \quad$ Smooth surface 


\section{THIS PAGE}

\section{WAS INTENTIONALLY \\ LEFT BLANK}


Appendix A

Digital Computer Program 
THIS PAGE

\section{WAS INTENTIONALLY LEFT BLANK}




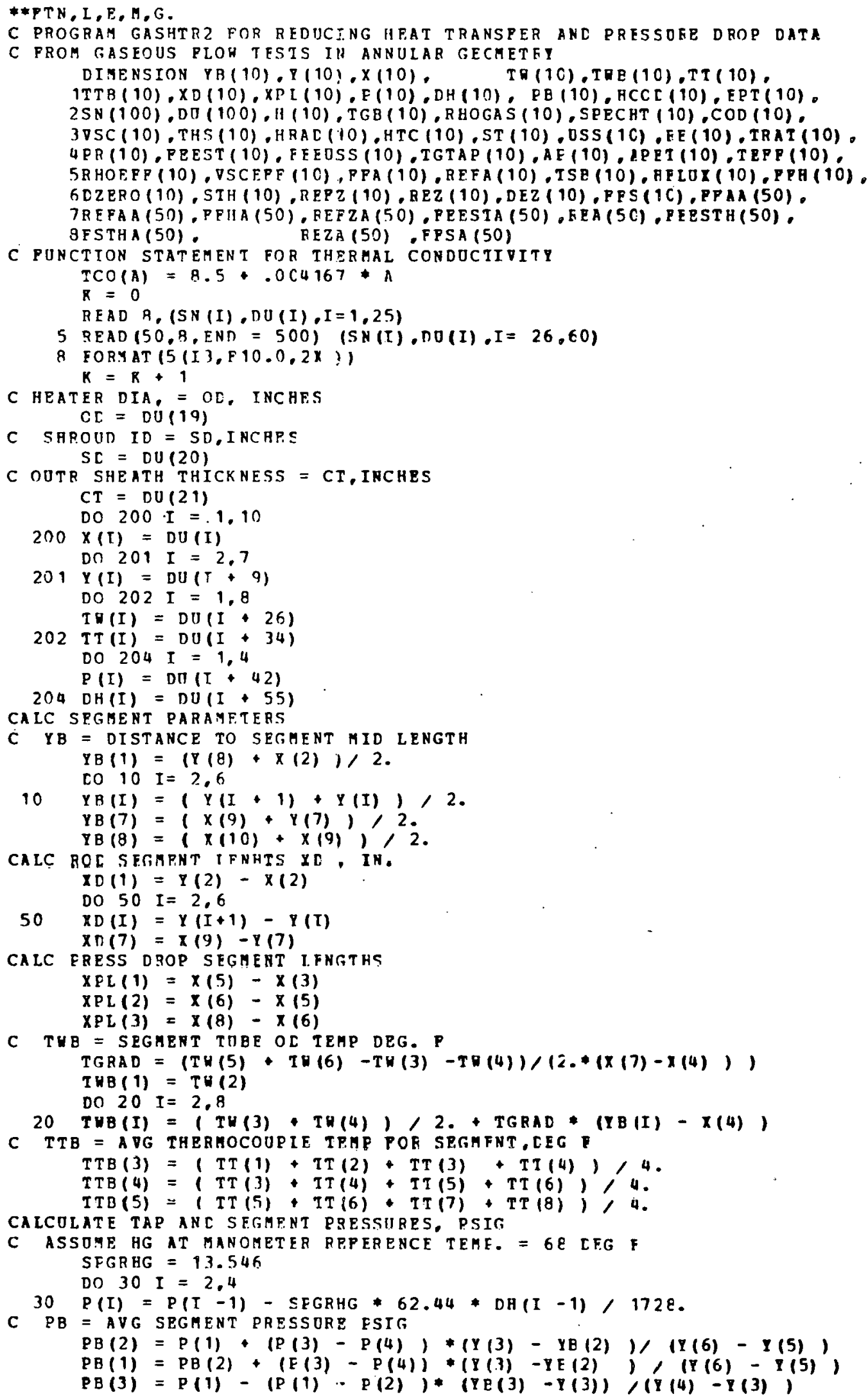




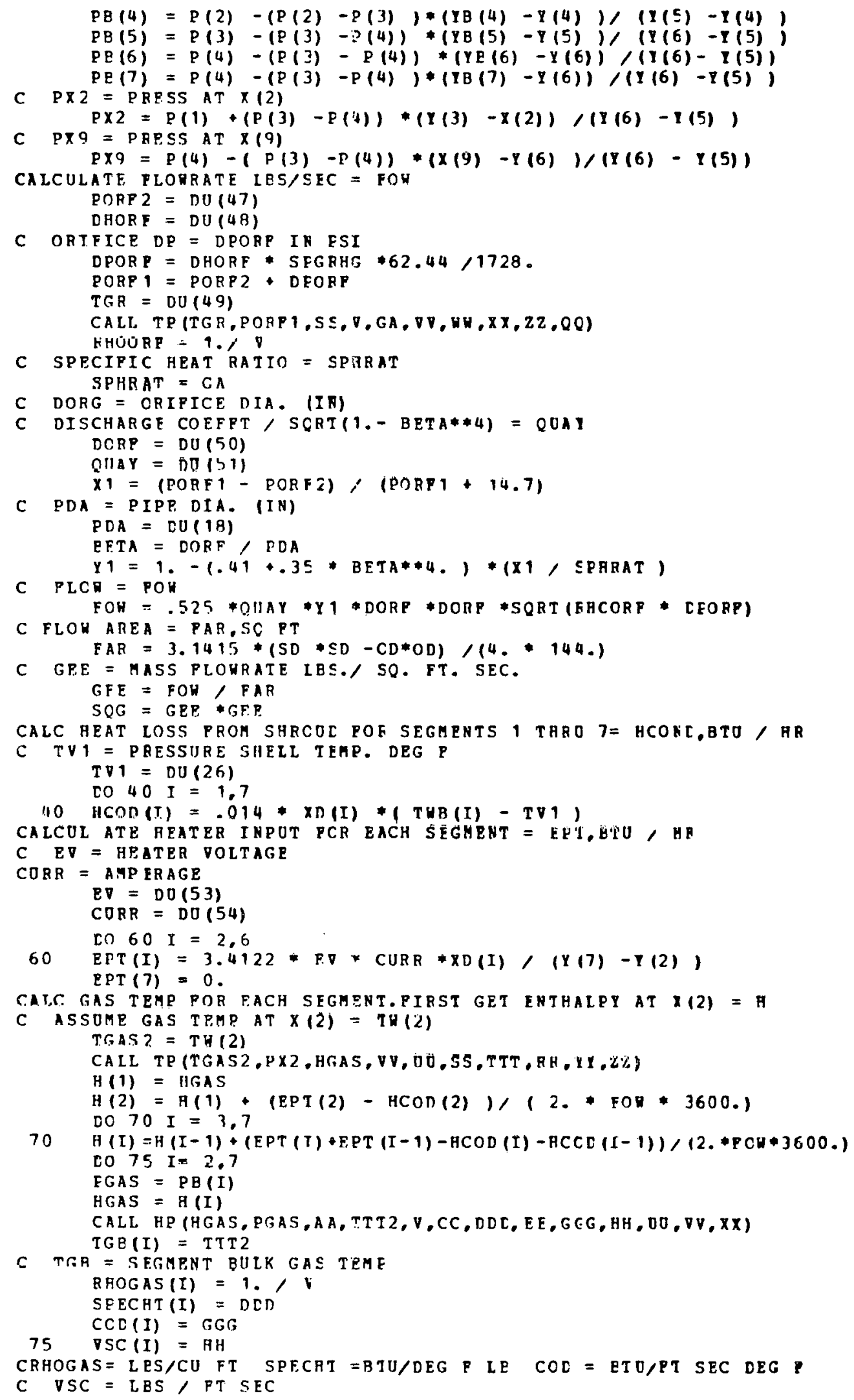


CALC HEAT BALANCE BETHEEN X(2) AND X (9).GBT ENTHALPI AT X(9)

CALL TP(TW(7),PX9,HGAS, DV,UO,SS,TTT,RR, IT,ZZ)

H (B) $=$ HGAS

AFGAS $=(H(8)-H(1)$ ) POD*3600.

C APGAS = GAS ENERGY GAIN BTO/ HR

C ERERGY LOSS FROM TUBE BETUER X(2) AND X(9) = SHCOC

$S H C O C=0$.

DO $80 \quad I=1,7$

BO SHCOD = HCOD (I) S SACOD

C HERROR = PRRCENT ERROF IN HEAT BALANCE

$E P \cap T=3.4122 * E V * C U R R$

HERROR = (EPIIT - SHCOD - AEGAS) * 100, / EPOT

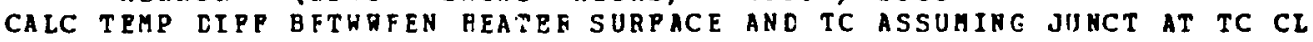

C TD = DIA AT HEATER TC CIRCIE, IN

$T D=O D-2 . *(.01+C T)$

DO $100 I=3,5$

TSS $=$ TTB (I)

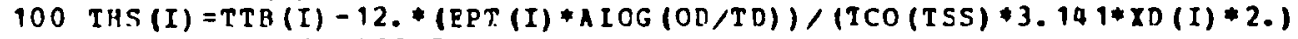

C THS = HEATER SURFACE TEMD TEG $P$

CALC. ROD SEGHERT RADIANT HRAT TRANSPER FOR GRAT ERCLCSURE EHA. $=.5$ LO $90 \quad I=3.5$

$\operatorname{co9} 9=((\operatorname{THS}(I)+460) / 100) * 4 ..-((\operatorname{T*Q}(\mathrm{I})+460) / 100) * 4$.

90 HRAD (I) $=.1415 * C D * \times D(I) * .4 * .171 * \operatorname{cog} / 144$.

C EQOIV DIA $=$ DEQ

$D E Q=S D-O D$

CALC SEGHERT PARMETERS HTC = HEAT TRANSPER CCEPI BTO/AB SQ PT DEG DO $110 \mathrm{I}=3,5$ HFLOX(I) $=(\operatorname{EPT}(I) \quad-H R A D(I)) * 144 . /(3.1415 * 0 D * X D(I))$ $H T C(I)=H P L O X(I),(T H S(I)-T G B(I))$

C NOSSELT = OSS, ST =STANTOR, RE =REY NOLDS,TRAT T T/TB, PB=EFANDTL $\operatorname{ST}(\mathrm{I})=\operatorname{HTC}(\mathrm{I}) /(\mathrm{SEECHT}(\mathrm{I}) * \mathrm{GEE} * 360 \mathrm{C}$.

$\operatorname{OSS}(I)=\operatorname{RTC}(I) * \mathrm{DEQ} / 143200 * \operatorname{COD}(\mathrm{I}))$

$\operatorname{RE}(I)=D E Q$ GEE $/(\nabla S C(I) * 12$.

TRAT (I) $=$ (THS(I) +460.$) /(T G B(I) \cdot 460$.

$\operatorname{PR}(I)=\operatorname{SPECHT}(I) * \operatorname{VSC}(I) / \operatorname{COD}(I)$

Co110 = 1

PEEST(I) $=$ ST (I) *PR (I)*.6*TRAT (I)* *C110

PEEST (I) $=$ ST (I)

$\operatorname{col} 11=.5$

110 RREUSS (I) = USS(I) *TRAT(I)**C0119/(PR (I)**.4)

CAIC TEMPS AND PRESS AT TAPS AND AVERAGE CVEF TAP SEGEENTS

C TGTAP = TEMP AT TA?

DO $120 \mathrm{I}=1,4$

$\operatorname{TGTAP}(1)=\operatorname{TGB}(2)+(\operatorname{TGB}(3)-\operatorname{TGB}(2)) *(x(3)-\operatorname{PE}(2)) /(X B(3)-\mathrm{YB}(2))$

$\operatorname{TGTAP}(2)=\operatorname{TGE}(3)+\operatorname{TGG}(4)-\operatorname{TGB}(3)) *(X(5)-9 B(3)) \cdot(\operatorname{PB}(4)-\operatorname{TB}(3))$

$\operatorname{TGTAP}(3)=\operatorname{TGB}(4)+(\operatorname{TGB}(5)-\operatorname{TGB}(4)) *(X(6)-$ YE $(4)) /($ PB $(5)-$ YB $(4))$

$120 \operatorname{TrTAP}(4)=\operatorname{TGB}(5)+(\operatorname{TgE}(6)-\operatorname{TgB}(5)) *(X(A)-\operatorname{TE}(5)) /(1 \mathrm{X}(6)-\operatorname{TB}(5))$

NORUN $=$ DT(55)

PRINT 125, NORUN

125 PORMAT (1H1.30X,'PRESSTRE DROP DATA RON ?.I3)

PRINT 127

127 PORMAT (1HO.'SEGMENT NO BB TEPF FHOEPP AF APNET PFA 1 REPA FEH DZERO RE ROL')

CALC NET PRESSURE DROP ACCOUNTING POR ACCELERATICN LO $130 \quad I=1,3$

$A P(I)=P(I)-P(I+1)$

CALL TP(TGTAP (I),F(I),CCC, V,DDD,FEE,GGG,OUD,VOV,VRU)

GASD $1=1$. $T V$

CAIL TP(TGTAP $([+1), P(I+1), C C C, V, \cap C D, P E E, G G G, 000, \nabla \nabla V, Q W D)$

GASD $2=1 ., V$

$\operatorname{CO} 130=1 . / \operatorname{GASD} 1-1 . / \mathrm{GASD} 2$

$\operatorname{col} 131=\operatorname{SQg} /(32.2 * 144$.

130 AEET (I) $=A P(I)+C C 130 * \operatorname{Co131}$

C. DECREASE AP1 TO ACCOUNT POF .0006 IN. INCREASE AT 19

PART $=3.1415 *(.6006 * .6006-C D * O C) /(4 . * 144$.

C0132 $=1$. - (PAR1, FAR)*2.

CORR $1=$ CO131*CC132/(RHOGAS $(3) * 2$.

$\operatorname{APET}(1)=\operatorname{APET}(1)+\operatorname{CORR} 1$ 
C INCEEASE AP3 TO ACCOONT POR .004 IN. INCREASE AT D4

PAR4 $=3.1415 *(.6 C 4 * .604-O D * O D) /(4 * * 144$.

C0133 $=($ PARU, FAF) *2. -1 .

CORR $3=\operatorname{COT33} * \operatorname{CO131/(RHOGAS}(5) * 2$.

$A P P T(3)=A P Q T(1)+\operatorname{CORE} 3$

C PIA PP WITU DFNS AND VISC BASED ON RPFECTIVE TEAE RUT ACTUAL PBLOCITI

$B \mathrm{E}=.05$

DO $150 I=3.5$

$\operatorname{TEPP}(T)=R B *(T H S(T)-T G B(I), \operatorname{TGB}(I)$

CALL TP(TEPF(I), PE(I),CC,V,DD,EE,GG,OU,VIG,VV)

BHOEFP $(I)=1 ., V$

PSCFPF $(I)=V I r$

CO150 = 2A8. * DEQ*RHOGAS (I) *RHOGAS (I) 32.2

$\operatorname{CO151}=$ XPL $(I-2) * S Q G *$ RAOEPF (I)

FPA (I) $=\operatorname{CO150*APET~}(I-2) / \operatorname{CO} 151$

$\mathrm{CO152}=\mathrm{GBE} * \mathrm{DEQ}, 12$.

CO153 = RHOEFE(I) / RHOGAS (I)

REPA (T) $=\operatorname{Co152*C0153/VSCEPP(I)~}$

C APPLI HALI TRAASEORA IC Z.P.

C UU = CHAHNEL PERIMETEE

DD $=3.1415 *$ (OD $+S D)$

C 0 OT = PERIKETER OUTEE CHANHEL

$002=3.1415 * 5 D$

OUX $=002, U \|$

C PFS = PP CORRELATEC FOR SMCOTH CHANNEL

FFS (I) $=.11 n *(R F F A(I) *(-.155)$ )

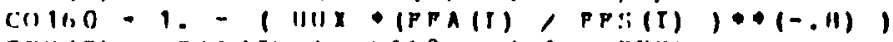

PYH II) = PPA(I) $(: 016,0),(1$ - IIIIX)

C CALC. ZFRO SHEAR TIIAETEQ = DZERO

$\operatorname{Co} 161=(S D * 2 .-C D * 2) * S D *.(F P A(I) /$ FPS $(I)) *(-.8)$

$\operatorname{DZPRO}(I)=(S D * 2 .-\operatorname{CO} 161 /(O D+S D)) * .5$

CALC RE BASED ON DZRRO = REFZ, DEZ = D, HYCRR. INNER CAARHEL $\operatorname{DEZ}(I)=(\operatorname{DZERO}(I) * 2 .-O D * 2),. O C$

RFPZ (I) = REPA (I) * DEZ (I) / DEQ

PRINT 160, I, EE, TEFE(I), RHOEPP (I), AP (I-2), APEI (I-2), PPA (I) .

1 REFA(I), PPH (I), EZFRO (I), REFZ (I)

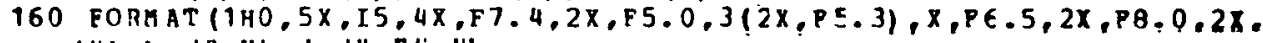

$1 l^{2} t, 3, J x, P(, I, J x, P(x, l)$

150 CONTINDE

DO $155 \mathrm{I}=3.5$

C APPLY HALI TRANSFORM TO STANTON RC.

$\operatorname{CO} 170=((S D / O D) * 2 .-1) *$.2 .

$\operatorname{Co171}=((S D / O D) * * 4) *.(4 . * A L C G(S D / C D)-3$.

$\cos 172=4$. $*(S D / C D) * 2 .-1$.

PEEONE $=\operatorname{co170,(\operatorname {cos}17+\operatorname {cos}12)}$

$\operatorname{CO} 180=($ (DZERO (I),$O D) * 2 .-1) *$.2 .

$\operatorname{CO181}=((D Z F R O(I) / C D) * 4) *.(4 . * A L O G($ CZERO (I) $/ O D)-3$.

$\operatorname{CO182}=4$. * (CZERC(I),$O D) * 2$. - 1 .

PERTHO $=\operatorname{Co180/(CC181+CO182)~}$

$\operatorname{CO} 185=(T H S(I)-T G E(I)) * \operatorname{COD}(I) * P P H(I) * G E F * 3600 . /(8$. $*$ VSC $(I) *$

1 HPLOX (I) I

STH (I) $=\operatorname{CO185/(|CC185-1.)*~PREORE/RRETHO~+1.)*ST(T)~}$

FEESTH (I) $=$ STH (I) *PR (I)**6*TRAT (I)*

PEESTH (I) $=$ STH (I)

CALC RE BASED ON DZERC = REZ

155 BEZ(I) = RE(I) * [EZ(I) / DEQ

FITNT 170, NORIN

170 PORMAT $(140,30 \mathrm{x}, \circ$ HeAT TRANSPER DATA RUN ?.I3) FRINT 172

172 PORMAT(1RO,'SEGAENT NO GAS PRESS GAS TEAP GAS LENS VISCOCITY ISURF TEMP SHROUD TEMP TG/TE')

PRINT 173, (I,PB (I) ,TGB(I),RHOGAS(I), VSC(I),THS(I),TWB(I),TRAT(I), $1 I=3,5$ )

173 PORMAT(1H0,4X,I2,8X,P7,2,5X,P6:1,4X,P6.4,3X,P9.8, 3X,P6.1,4X,P6.1. $16 x, 75.3)$

PRINT 174 


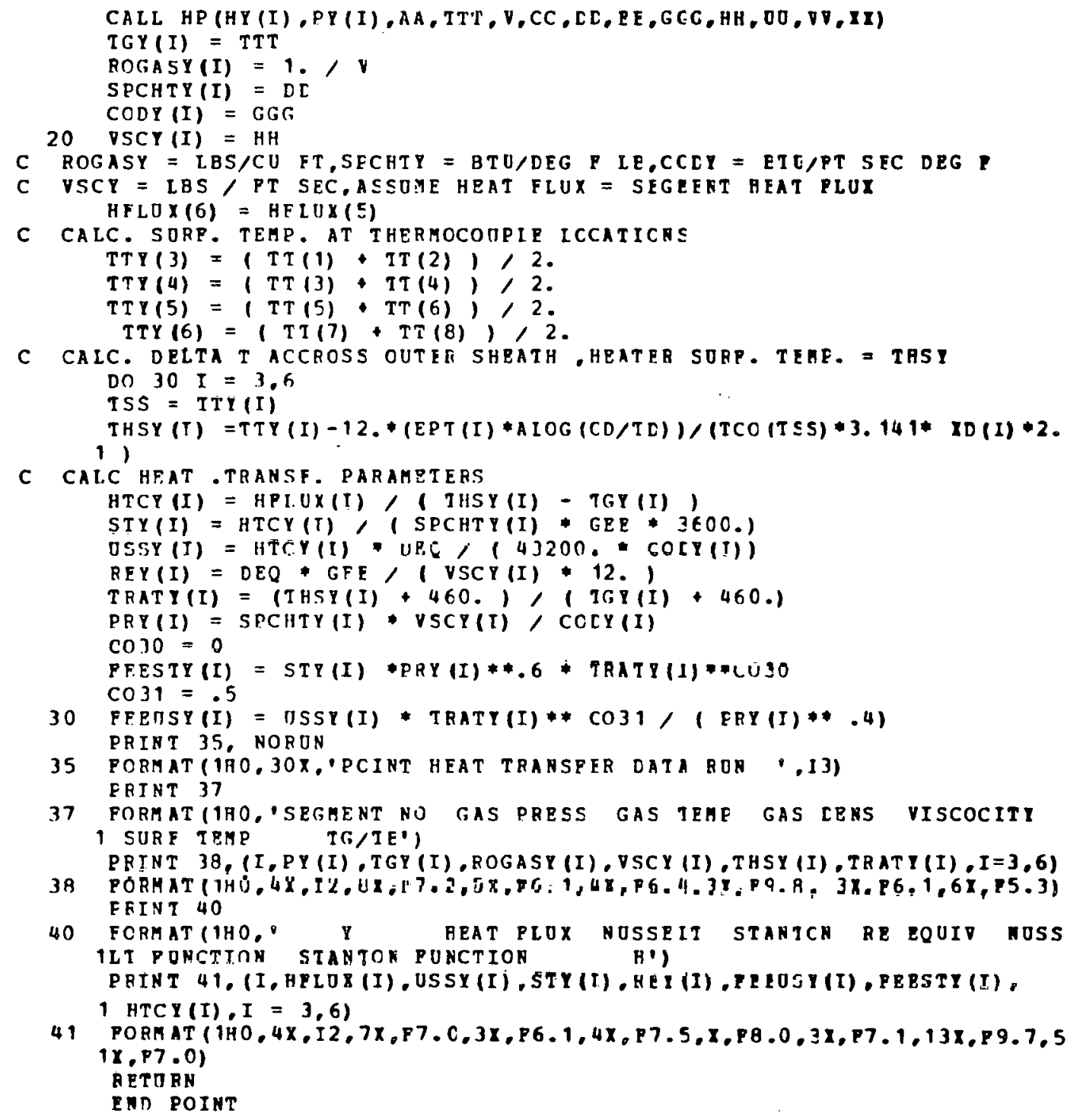



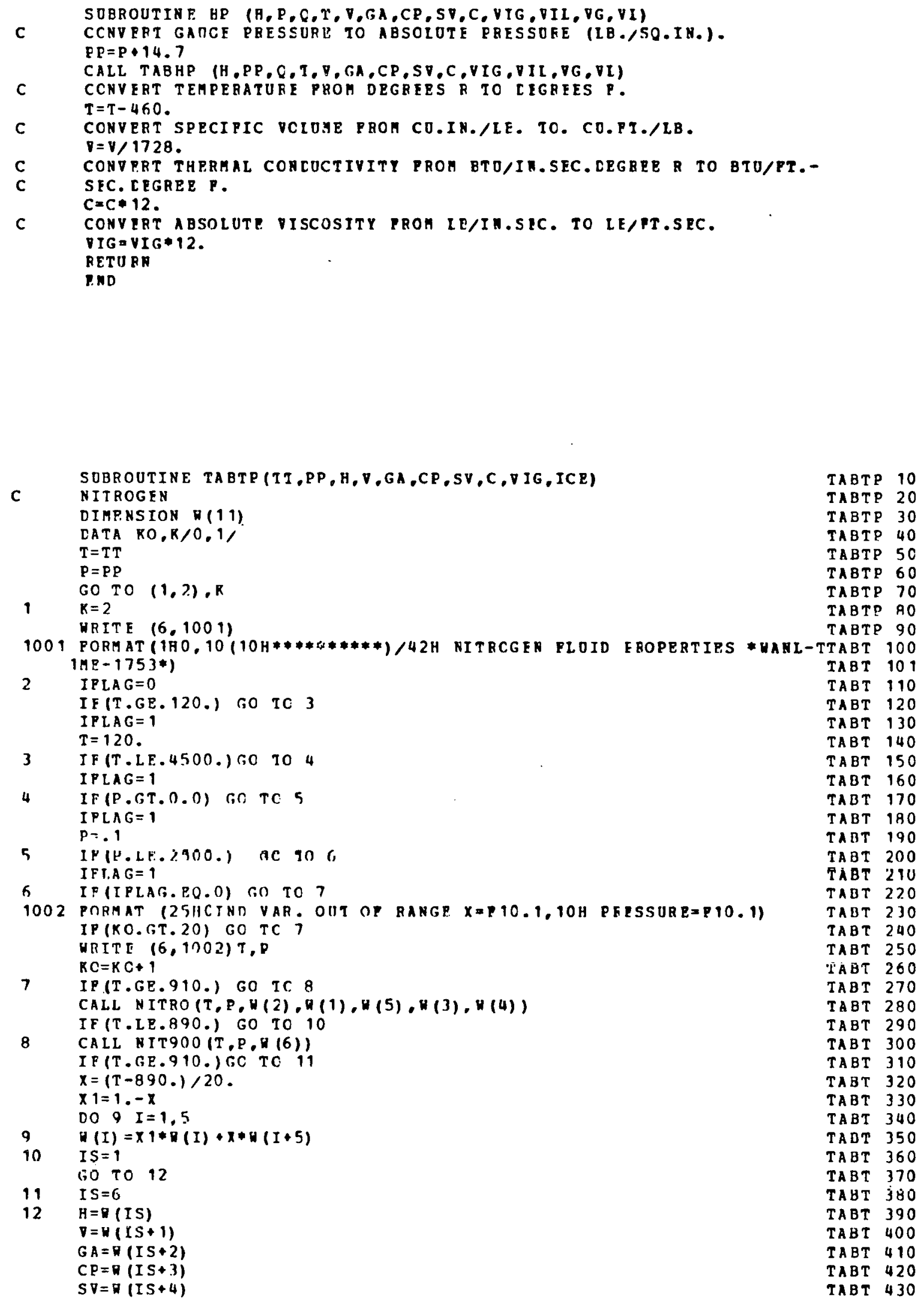


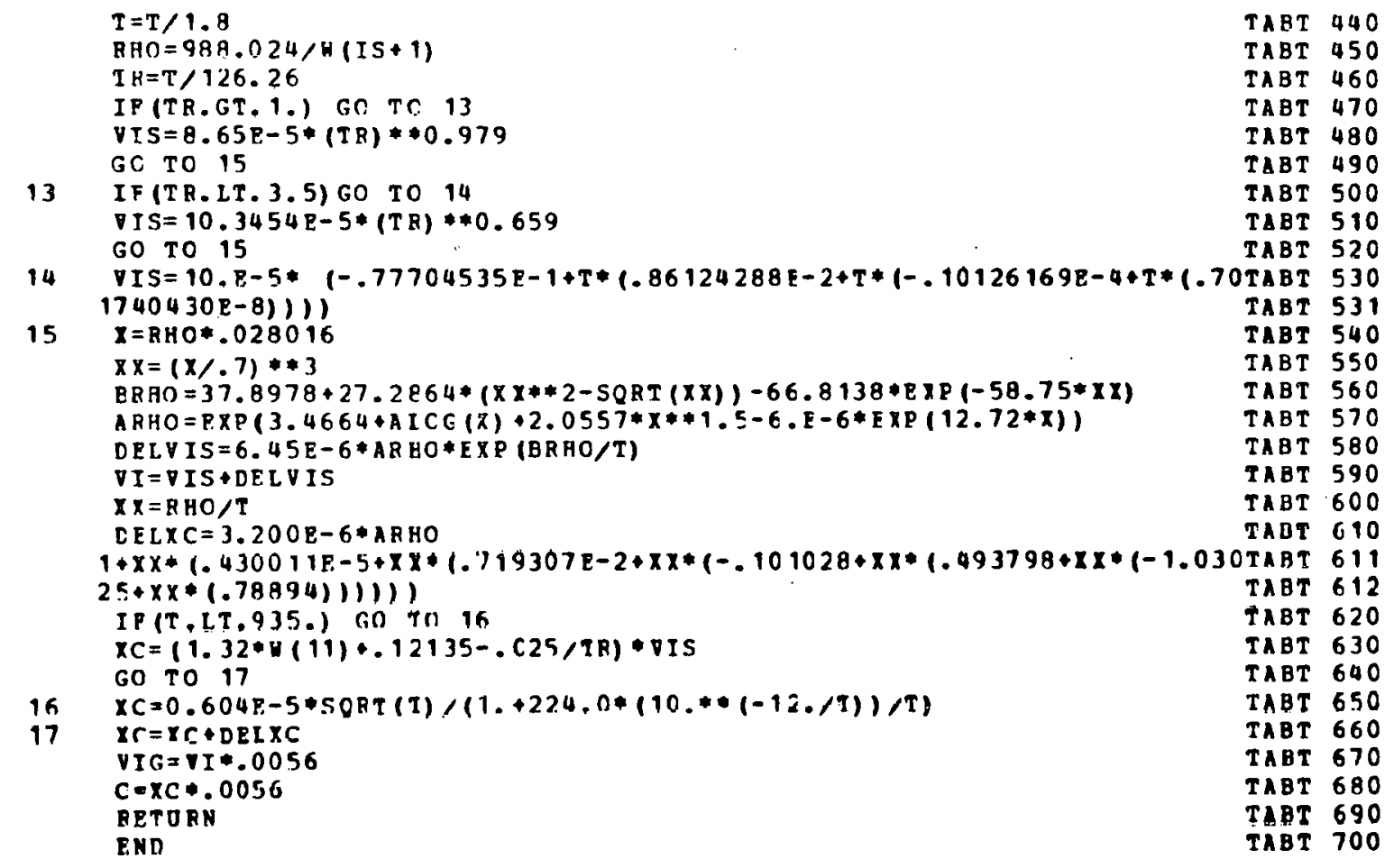


$2178.00 .200 \cdot 16.272 .51 .348 .77$.

TABH 102

$3197.00,216.24 .281 .72,354.32$.

TABH 103

$4210.00,230.28 .290 .24 .359 .88$.

TABH 104

5220.00 .242 .52 .298 .14 .365 .43 .

$6228.26,253.20,305.42,37$ C.98/

TABH 105

RCUN T $=0$

$T C R=110$.

$Q 0=1$.

$K R=0$

$\triangle \mathrm{LP}=8$.

$\mathrm{H}=\mathrm{HH}$

$P=P P$

IP (H.LT. 150.) GO TO 6

$P P=P / 500$.

IF (H.LT.300.) CO TC 5

$F H=(H-300) /$.260 .

$I G=1$

$1 \quad I T=P H$

$I P=F P$

$P H=A$ UOD ( $P$ H, 1.)

$F P=A$ HOD $(F P, 1$.

IP (H.GE.1340.) GO TO 3

2

IP (P.GT.2500.) GO TC 4

GC TO 13

$3 \quad I G=1$

$\mathrm{I} T=3$

$P H=(H-1340) / 260 .$.+1 .

GO TC 2

I $P=5$

$F E=(F-2500) /$.

IP (A.IT. 150.) I $P=4$

GO TO 13

$5 \quad P H=(B-150) /$.50 .

$I G=2$

GO TO 1

6 IP (P.LT.500.) GO TO 8

$F F=(P-500) /$.500 .

$F \mathrm{~F}=(\mathrm{B}-10) /$.20 .

$I G=3$

GO TO 1

8 IP(H.IT.11.0.) GO TO 10

$F P=P / 100$.

$P A=(B-11 \cap),$.130 .

$I G=4$

GO TO 1

10 IP(P.GP.493.14) GC TO?

IF (H.LE.3.) GC TO 7

I P (H.GE.105.) GO TS. a

$X=33.556-P / 14.696$

TABH 105

TABH 110

TABH 120

TABA 130

TABR 140

TABH 150

TABA 160

TABH 170

TABH 180

TABH 190

TABH 200

TABH 210

TABH 220

TABY 230

TABY 240

TABH 250

TABH 260

TABH 270

TABH 280

TABH 290

TABB 300

TABH 310

TABA 320

TABY 330

TABB 340

TABR 350

TABE 360

TAB日 370

TABH 380

TABA 390

TABH 400

TABH 410

TABH 420

TABH 430

TABA 440

TABH 450

TABB 460

TADIl 470

TABH 480

TABR 490

TABB 500

TABH 510

TABH 520

TABH 530

TABB 540

$T T=(E X P(4.8293+X * 1.619608 E-2+X *(-.21951 E-2+X * 1.124206 E-3-X * .23531 F T A B H 550$

$(-5)) 1) \neq 1.8$

TABR 551

$11 \mathrm{PL}=\quad(\mathrm{EXP}(\mathrm{A}(1)+\mathrm{A}(2) / T \mathrm{~T}+\mathrm{TT} *(\mathrm{~A}(3)+\mathrm{T} *(\mathrm{~A}(4)+\mathrm{T} * 1 \mathrm{~A}(5)+\mathrm{TT} *(\mathrm{~A}(6)+\mathrm{TT} * \mathrm{TABA} 560$

$((A(7))))) * 2.3025851)) * 14.696$

$D P D T=P L * 2.3025851 * 1-A(2) / T T * 2+A(3)+T T *(2 . * A(4)+T T *(3 . * A(5)+T T *(4 . T A B R 570$

$1 * A(6)+T T *(5 . * A(7)))))$

IP (ABS $(P-P L) \cdot L T .0 . C 01)$ GO TO 12

$T T=T T \cdot(P-P L) / D E C T$

KUUN T $=$ KOUNT +1

IF (KOUNT.LT.20) GC TO 11

12 CALL TABTP (TT-.01,P,HF, VL,OAL,CPI,SVL,CI,VIL,ICE)

KOURT $=0$

IF (H. IT, HP) GO TO 14

CALL TABTP (TT•.01,P,HG,VG,GAA,CPP,SVV,CC,VIGG,ICE)

IF (H.GT.HG) GO TO 22

$Q Q=(B-A P) /(B G-B P)$

$V V=Q Q * V G+(1,-Q O) * V I$

GO TO 25

TABR 571

TABR 580

TABH 590

TABA 600

TABH 610

TABH 620

TABA 630

TABH 640

TABH 650

TABH 660

TABH 670

TABA 680

TABH 690 . 


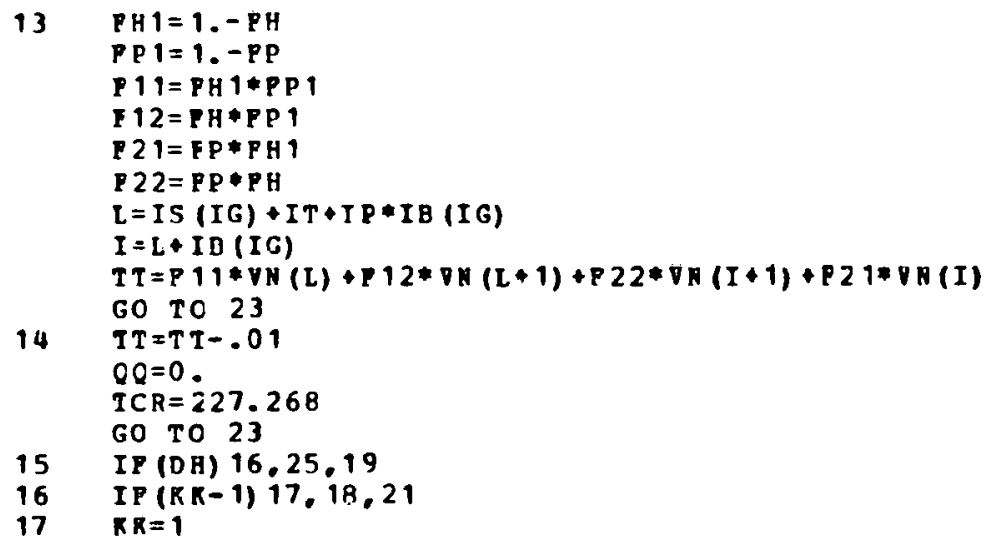

TABA 700

TAB 710

TABB 720

TABII 730

TABH 740

TABF 750

TABH 760

TABH 770

TABH 780

TABH 790

TABR 800

TABH 810

TAB日 820

TABA 830

TABA 840

TABB 850

TABB 860

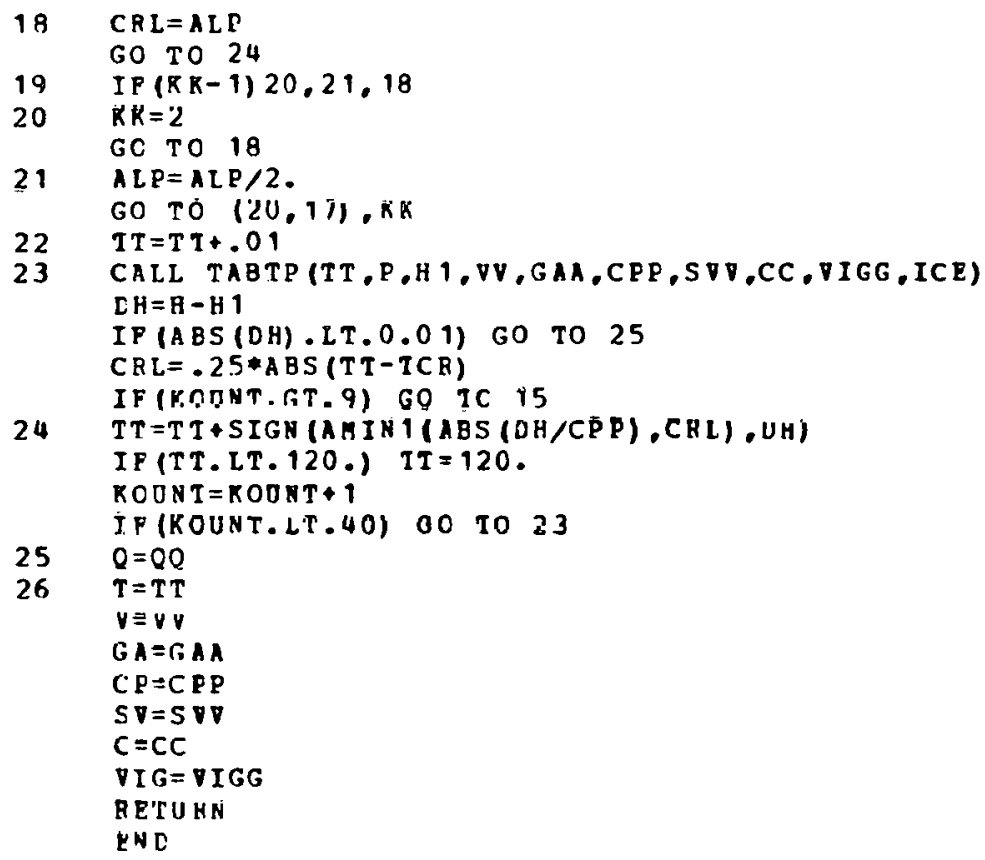


$2(((20 . * X N(14) / T+12 * x *(13)) / T+6 . * X N(12)) / T S 5) * 111$

XTER 132

$X 2=(\{(5 . * X N(5) / T S+3 * \pi N(4)) / T+2 * X N(3)) / T+X N(2)) * X 7$ *

XTER 140

$1 \times N(7) *(\times 3-\times 4) / 2$.

$2((15 * X N(11) / T+4 * X N(10)) / T+3 * X N(9)) / T S) * \times 10 *$

XTER 141

$3((15 * \times N(14) / T+4 * X N(13)) / T+3 . \times \times(12)) / T S) \neq X 11$

XTER 142

$4+X *(15) *(X 3 * x 3 * R$ B H $-X 4 * X 4 * R$ H $) / 5$ 。

BETU RN

XTER 143

XTER 144

END

XTEB 150

ITER 160

SUEROUTINE NIT TOO (TI, RP, D)

HIT $90 \quad 10$

RANGE TEMP 900 TO 4500 DFG RARINE - PEESSURE C-2500 PSIA NITRO NIT90 20

CIMENSION $H(6), \nabla N(1 \leq 5)$

DI KFNSION VN 130$), \nabla N 2(30), \nabla N 3(30), \nabla N 4(3 C), \nabla N 5(5)$

NIT 9030

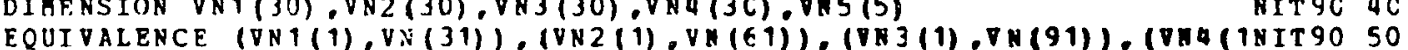

1). VN (121)), (VN5(1), VN (151)) F.NTHALPY RTU/LE

LATA (VN (I) $, I=1,30)$,

$1288.69 .527 .39 .787 .42 .10 \leq 9.56 .1338 .29$,

$2287.93 .528 .30 .788 .88 .1061 .30 .134 \mathrm{C} .19$.

$3287.29 .529 .25 .790 .37,1063.08 .1342 .14$.

4286.80 .530 .22 .791 .86 .1064 .84 .1344 .07 .

$5286.44 .531 .19 .793 .34,1066.58,1345.99$,

$6286.19 .532 .18 .794 .80,1068.31,1347.89$,

COMPRESSIBILITY FACIOR $Z=P * \nabla /(R * T)$

DATA VNI/

$11 \ldots 1 \ldots 1 . .1 \ldots 1 \ldots$

$21.01497 .1 .01404,1.01086 .1 .00871 .1 .00724$.

$31.03099,1.02796,1.02157,1.01732,1.01441$.

$41.04790,1.04174,1.03216,1.02583,1.02151$.

51.06555 .1 .05540 .1 .04263 .1 .03425 .1 .02853 .

$61.08379,1.05892,1.05297,1.04257,1.03549$,

SPECIFIC HEAT RATIC GA=CP/CV

CATA VN2/

11.392 .1 .341 .1 .313 .1 .301 .1 .294$.

$21.412,1.345,1.315,1.302,1.294$.

$31.430,1.350,1.317,1.303 .1 .295$.

$41.447,1.354,1.319,1.304,1.29 \epsilon$.

$51.461 .1 .358,1.321 .1 .305 .1 .29 \epsilon_{\text {, }}$

61.474 .1 .361 .1 .322 .1 .306 .1 .297 ,

SPECIEIC REAT -CP-

DATA VN $3 /$

$1.25230,27878 . .29708 . .36670 .031222$.

$2.25609, .27970, .29749, .30693 \ldots 31237$,

$3.25964 .020060 \% 29790 . .30117 \% 31253$.

4. 26282,.28144,.29E3C,.3C741,.31268.

$5.26567 \ldots 28224 \ldots 2986 \% \ldots 3 C 764 \ldots 31283$,

$6.26821 \ldots 28300 \ldots 29906 \ldots 30787 \ldots 31298 /$

SCNIC VELOCITY

IATA VNU/

$117893 . .24834 \ldots 30097.034594 \ldots 38573 \ldots$

$218153 . .25243 . .30283 \ldots 34758 \ldots 38712 \ldots$

$318413 . .25264 . .30465 .334919 .038864 \ldots$

$418673 . .25470 \ldots 30646 \ldots 35078 \ldots 39015 \ldots$

$518921 \ldots 25499 \ldots 3082 \mathrm{E} \ldots 35235 \ldots 39148 \ldots$

$619167 . .25867 . .30989 .035389 .39296 .1$

SPECIFIC HEAT - CVC-

DATA VN $5 / .18125 \ldots 20788 \ldots .22626 \ldots 23574 \ldots 24128 /$

$T=T T$

$P=P P$

$P T=(T-900) /$.900 .

$P P=P / 500$.

$I T=P$ T

$I P=P P$

$P T=A$ mกn $(P T, 1$,

NIT $90 \quad 51$

NIT 9060

NIT90 70

NIT 9071

NIT90 72

NIT90 73

NIT90 74

NIT90 75

NIT90 76

NIT 9080

NIT 9090

NIT 9091

NIT 9092

NIT 9093

NIT9C 94

NIT $90 \quad 95$

NIT 9096

NIT 100

NIT 9110

NIT9 111

NIT9 112

NIT9 113

NIT9 114

NITY 115

NIT9 116

NIT9 120

NIT9 130

NIT9 131

HIT 132

NIT9 133

NIT 134

NIT9 135

NIT9 136

NIT9 140

NIT9 150

NIT 151

NIT9 152

NIT9 153

NIT9 154

NIT9 155

NIT9 156

RIT9 160

คIT9 170

NIT 980

NIT 190

NIT 200

BIT9 210

NIT 9220

NIT9 230

NIT9 240

$P P=A$ HOD $(P P, 1$.

HIT9 250 
IF (T.LE.4500.) GO IC 1

$I T=3$

$T R=(T-4500) /$.900 .

$F T=T R+1$.

1

IF (P.LE. 2500.) GO TC 2

I $P=4$

$\vec{P}=(P-2500) /$.500 .

$P P=P E+1$.

2

$P T 1=1 .-P T$

$P P 1=1,-P P$

$P 11=P T 1 * P P 1$

$F 12=P T * P P 1$

$P 21=P P * P T 1$

$F 22=P P * P T$

$I=1+I T+I P * 5$

nn $3 k=1.5$

$J=L *(R-1) * 30$

$I=J+5$

$3 W(K)=F 11 * \nabla R(J)+F 12 * V N(J+1)+F 22 * \nabla N(I+1)+F 21 * V$ 月 $(I)$

$N(2)=661.95 * D(2) * T / F$

$L=151+I T$

$V(6)=P T I * V N(L)+B T * V N(L+1)$

HETURN

EN C

DATA HID/202,86,525.25,847.11,1169.4,1454.1,1827.5,2177.2,2551.4, $12959.5,3396.5,3648.0,3942.8 .4241 .3,4437.5,4497.1,4562.5,4601.0 /$

DATA CVID/29.7,27.8.25.7.26.0.25.4.24.2.24.1.23.9,

$124.727,26.118,27.3 \mathrm{CE}, 28.649,3 \mathrm{C} .180,31.174,31.474,31.804 .32 .000 /$

$T=T E M E / 1.8$

$P=$ PRPS $/ 14.696$

$R T=P * T$

$T S=T * T$

$T S S-T S * T$

$J=0$

I T Y $P F=1$

$C P O=2.910996 \mathrm{~F}+1+T *(\cdots 8.0820995 \mathrm{E}-4+T+18.61420378-G$ I $T=$

$1(-3.689372 R F-8+1 * 5.6750880 \mathrm{E}-111))$

$H C=4226.3003+T *(29.109996+T *(-4.0410497 R-4+T+12.8714012 P-G+T * P$

$1-.9223307 E-8+1+(1.1350176 \mathrm{E}-11)) 1) 1$

$C \nabla O=C P O-R, .00986896$

IP (T.GE. 126.26) GO IC V

HITRO 20

NIT RO 30

NITBO 40

HITBO 50

NIT RO 51

NITHO 32

NITRO 60

NITRC 61

HITRO 70

NITRO 71

NITRO 80

NITRO 90

NITR 100

NITR 110

NITR 120

NITR 130

NITR $140^{\circ}$

NTTR 150

NTTR 151

NITA 160

คITR 161

NITR 170

$x=$

$(X J(1)+x).(2), T+T *(X J(3)+T *(X . T(4)+T *(X J(5)+I *(X J(6)+T * X J(7)))$

NITR 180

1))

$\mathrm{PP}=10 . * \mathrm{x}$

IF (P.LT.PP) GO TO

PSAVE $=P$

$\mathrm{P}=\mathrm{PP}$

ITYPE $=2$

$x=(1 .-T / 126.26) * * .333 .3333\}$

$R H O=X K(1)+X *(X K(2)+X *(X K(3)+x *(X K(4)+X *(x *(5))))$

GO TC 2

$1 \quad \mathrm{RHO}=\mathrm{P} / \mathrm{RT}$

$2 \quad A=R * X N(1) * T+X N(2)+((1 X N(5) / T S+X N(4)) / T+X N(3)) / T)$

$B=R * X N(6) * T * X *(7)$

ATTR 191

aItr 200

NITR 210

NITR 220

NITR 230

NITR 240

NIT 250

NITR 260

NITR 270

NITR 280

$F=X N(B) * T$

NITR 290

NITR 300

NITR 310 


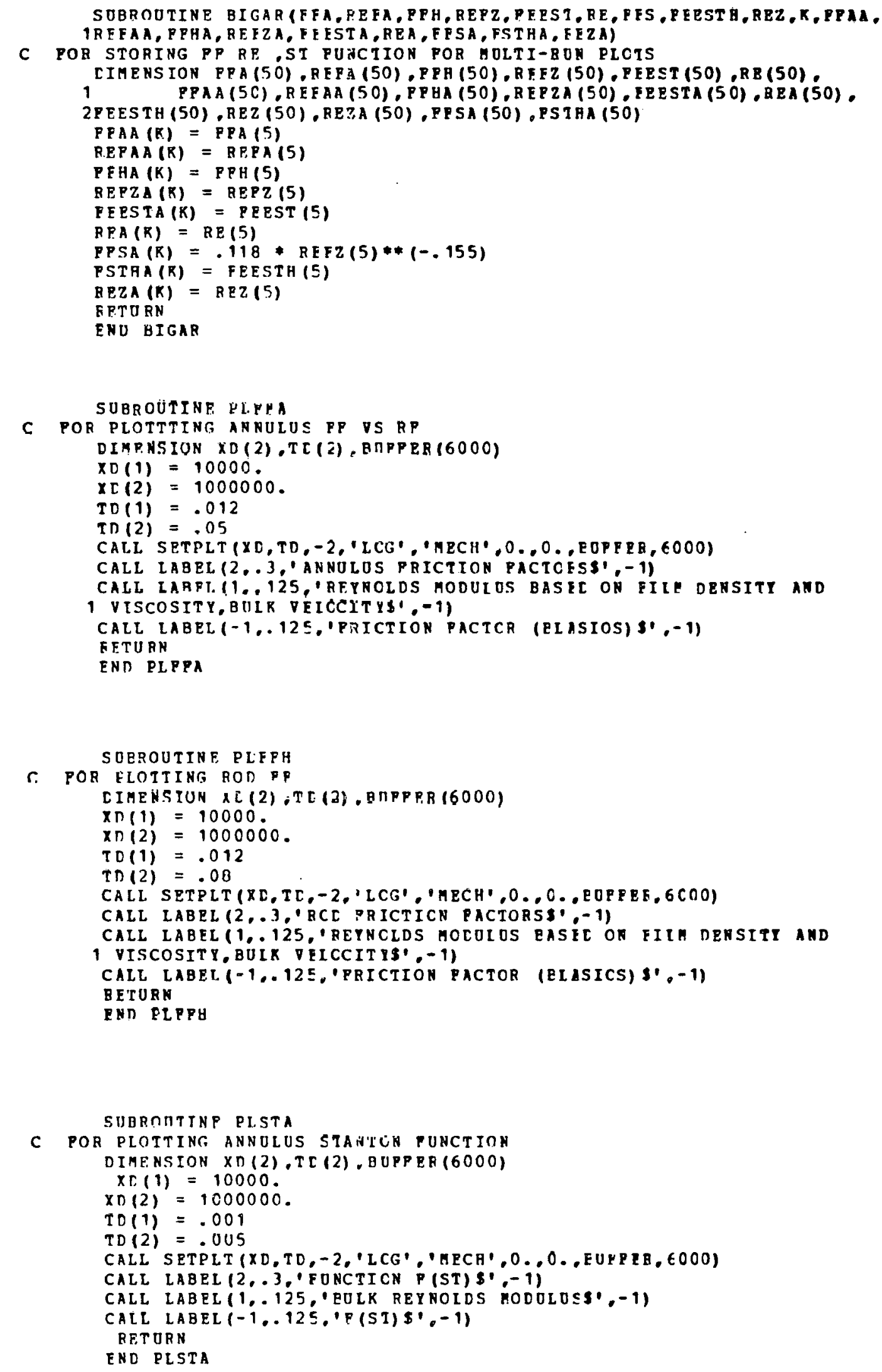


SOEROUTINE PLSTAB

POR FLOTTING ROD STARTCN PONCTION

DIRENSION XD(2), TC (2), BUFPER (6000)

$X C(1)=10000$.

$X D(2)=1000000$.

$T D(1)=.002$

$T D(2)=.008$

CALL SETPLT (XD,TD, -2, 'LCG', 'RECH',0, 0, EOFEEE,COOO)

CALL LABRL $\left(2, .3,0^{\circ}\right.$ OCTICA P(ST) $\left.\$ 1,-1\right)$

CALL LABEL $(1,125$, 'BULK REYMOLES MODOLOS\$,, 1$)$

CALL LABEL $(-1, .125$, P (SI) $51,-1)$

RET ORN

ERD PLSTAH 


\section{THIS PAGE}

\section{WAS INTENTIONALLY \\ LEFT BLANK}




\section{INTERNAL DISTRIBUTION}

1. T. D. Anderson

2. H. F. Bauman

3. S. E. Bea11

4. R. F. Bennett

5. R. H. Chapman

6. D. L. Clark

7. S. K. Combs

8. W. B. Cottrell

9. G. G. Fee

10. M. H. Fontana

11. A. P. Fraas

12. D. D. Gray

13. M. J. Goglia

14-18. H. W. Hoffman

19. R. S. Holcomb

20. L. Jung

21. P. R. Kasten

22. G. J. Kidd, Jr. $(\mathrm{K}-25)$

23-42. O. H. Klepper

43. T. S. Kress

44. M. E. LaVerne

45. C. G. Lawson
46. R. N. Lyon

47. R. E. MacPherson

48. W. J. McCarthy

49. H. A. McLain

50. S. L. Milora

51. R. C. Robertson

52. M. W. Rosentha1

53. J. P. Sanders

54. W. K. Sartory

55. J. D. Sheppard

56. M. J. Skinner

57. I. Spiewak

58. J. J. Taylor

59. D. G. Thomas

60. D. B. Trauger

61. J. P. White

62. G. D. Whitman

63. W. J. Wilcox

64-65. Central Research Library

66. Document Reference Section

67-69. Laboratory Records Department

70. Laboratory Records Department (RC)

\section{EXTERNAL DISTRIBUTION}

71. Research and Technical Support Division, ERDA, ORO

72. Director, Reactor Division, ERDA, ORO

73-74. Director, Division of Reactor Research and Development, ERDA, Washington, DC 20545

75-218. For distribution as shown in TID-4500 under category UC-77, Gas Cooled Reactor Technology 